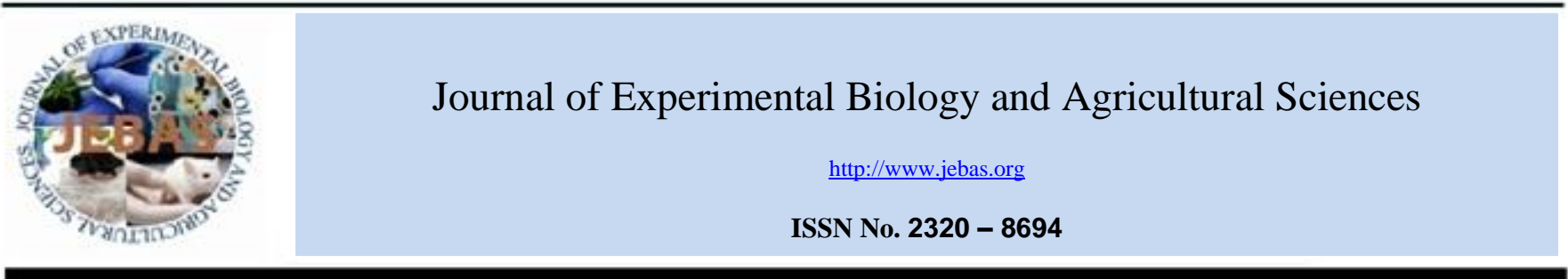

\title{
CURRENT KNOWLEDGE ON NANODELIVERY SYSTEMS AND THEIR BENEFICIAL APPLICATIONS IN ENHANCING THE EFFICACY OF HERBAL DRUGS
}

\author{
Sonu Ambwani ${ }^{1 *}$, Roopali Tandon ${ }^{2}$, Tanuj Kumar Ambwani ${ }^{3}$, Yashpal S. Malik ${ }^{4}$
}

\begin{abstract}
${ }^{1}$ Department of Molecular Biology and Genetic Engineering, College of Basic Sciences and Humanities, GB Pant University of Agriculture and Technology, Pantnagar 263145, Uttarakhand, India

${ }^{2}$ Department of Chemistry, Bareilly College, MJP Rohilkhand University, Bareilly, Uttar Pradesh, India

${ }^{3}$ Department of Veterinary Physiology and Biochemistry, College of Veterinary and Animal Sciences, GB Pant University of Agriculture and Technology, Pantnagar 263145, Uttarakhand, India

${ }^{4}$ Division of Biological Standardization, ICAR-Indian Veterinary Research Institute, Izatnagar 243122, Uttar Pradesh, India
\end{abstract}

Received - January 19, 2018; Revision - February 04, 2018; Accepted - February 06, 2018

Available Online - February 20, 2018

DOI: http://dx.doi.org/10.18006/2018.6(1).87.107

KEYWORDS
Herbal drugs
Nanodelivery systems
Liposomes
Phytosomes
Solid lipid nanoparticles
SPION
Dendrimers

\begin{abstract}
Herbal remedies have been extensively used since times immemorial throughout the world. These have wide acceptability due to their time-tested therapeutic values and minimal side effects in contrast to modern allopathic medicines. Commonly, the herbal medicines are available in the form of crude extracts prepared in different solvent systems which might not only need large dose administration but also could be less effective in the form of conventional formulations. Moreover, available phytoformulations do not have the ability for specific tissue target delivery in case of different chronic diseases. Oral administration of these herbal formulations is subjected to adverse $\mathrm{pH}$, enzymatic degradation and ultimately poor gut absorption and bioavailability. With the advancements in biotechnology, genomics, and combinatorial chemistry, new, more potent and specific drug delivery systems have been envisaged during the last few decades. Constraints associated with conventional phytopharmaceuticals have been improved by designing and using "Nano Delivery Systems" (NDS). The foremost aim of NDS is to provide sustained drug release, site-specific action, and improved patient's compliance. Nano herbal medicines can be used to target them to the specific site in the body which improves their selectivity, solubility, delivery, safety, effectiveness and thus reduces the need for
\end{abstract}

* Corresponding author

E-mail: ambwani_sonu@rediffmail.com (Sonu Ambwani)

Peer review under responsibility of Journal of Experimental Biology and Agricultural Sciences.

Production and Hosting by Horizon Publisher India [HPI] (http://www.horizonpublisherindia.in/).

All rights reserved.
All the article published by Journal of Experimental Biology and Agricultural Sciences is licensed under a Creative Commons Attribution-NonCommercial 4.0 International License Based on a work at www.jebas.org.

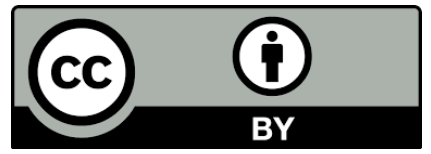


administration of frequent large doses. Nanocarriers loaded with herbal drugs can carry the optimal amount of the drug to their site of action avoiding different obstructions such as low $\mathrm{pH}$ in the stomach, metabolism by liver so that the drug can circulate into the blood for a longer period of time. Phytopharmaceuticals with NDS thus would be helpful in enhancing the efficacy of herbal drugs.

\section{Introduction}

From last decade there has been a wide acceptance and public interest in natural remedies both in developing and developed countries. As per World Health Organization (WHO) "herbal medicines as finished, labeled medicinal products that contain active ingredients, aerial or underground parts of the plant or other plant material or combinations". According to WHO reports, $80 \%$ of the populations from developing countries exploit herbal medicines for their primary health care needs (Yadav et al., 2014). Herbal 'renaissance' is happening all over the world due to rising concern over the safety of modern allopathic medicines. Various modern medicines are causing side effects and not able to effectively treat many of the common health conditions with increased incidences of drug resistance. Even the genesis of modern medicine is from traditional therapeutic systems (Patwardhan et al., 2004). Plants and natural products have been used since long for curative/ healing purposes in different cultures like China, Egypt, Africa, America and India. Herbal medicine, also known as "herbalism" or "botanical medicine" is a medical system based on the use of plants or plant extracts that may be taken orally or applied to the skin (Griggs, 1982). In spite of criticisms regarding certain features of herbal medicine, many pharmacologists today, recognize the potential scientific rationale of biological effects produced by these phytomedicines (Sharma et al., 2011).

Though herbal medicines are considered as dependable and affordable therapeutics, however, some problems are associated with them viz. rapid release of the herbal drug, unknown toxicity, low solubility, poor bioavailability and oral absorption, etc. (Thillaivanan \& Samraj, 2014). Besides the general notion that "the herbal drugs are safe", many pharmaco-vigilance studies have suggested that these natural drugs have frequently unknown active ingredients and thus their standardization and quality control are not an easy task (Ekor, 2013; Mathur, 2016). Delivery of herbal medicines also requires an improved delivery system for their sustained release and targeted delivery for enhanced patient compliance (Goyal et al., 2011). NDS is a new concept of drug delivery that can be helpful in surmounting the shortcomings of the traditional drug delivery systems. NDS, when employed for herbal medicine, may be helpful in enhancing the efficacy and lowering their side effects (Ansari et al., 2012). In novel phytoformulations, various nano delivery vehicles, viz., liposomes, polymeric nanoparticles, nanoemulsion, nanospheres, solid lipid nanoparticles (SLNs), are used in which phytoconstituents can be incorporated and these nanosized herbal formulations not only help in sustained release of the drug but can also eliminate the inadequacies of conventional herbal formulations (Elmowafy et al., 2013; Priprem et al., 2015). Present communication deliberates upon various nano delivery systems that could be exploited to eliminate shortcomings of conventional herbal formulations and thus can be helpful in improvement of therapeutic efficacy of phytomedicines.

\section{Advantages of herbal drugs}

Herbal medicine based therapeutic system is the ancient form of health care system known to human civilization. Phytoformulations may contribute immensely to the health of an individual (Mathur, 2016). An exponential increase in human population, insufficient availability of costly allopathic drugs, associated side effects and problems like multidrug resistance amongst infectious pathogens have led to the development of alternative plant-based natural medicines for a broad range of diseases (Greenwell \& Rahman, 2015). Phytomedicine or phytopharmaceutical, is a complex mixture derived from plant sources that is used as a medicine or drug. Approximately $50 \%$ of the functional drugs are prepared from natural resources (Kingston, 2011).

Herbal formulations are cost effective and made up from natural ingredients that are readily metabolized in the body. Herbal preparations have been recognized for their potential curative and low side effects in comparison to other drugs (Mahima et al., 2012). Herbal drugs are reputed for treating diverse disease conditions associated with various systems like endocrine, skeletal, digestive, physiological, nervous, reproductive, respiratory and immune systems. These biological properties of herbal drugs are attributed to the biological activities of various secondary metabolites like phenolics, terpenoids (sapogenin), alkaloids, steroids etc., present in them (Mathur, 2016). Herbal products can also be used to increase the bioavailability of the medicine (Kesarwani \& Gupta, 2013). 


\section{Constraints of herbal drugs}

Many herbal formulations are crude preparations with hydrophobic phytoconstituents and thus exhibit low solubility. Several other tribulations such as low solubility, bioavailability, and oral absorption lead to reduced efficacy which can limit the use of herbal medicines (Jantarat, 2013). Till recently, phytopharmaceuticals were not preferred for development of novel formulations due to their crude combinations that lack scientific rationalization and processing difficulties (Ekor, 2013; Thillaivanan \& Samraj, 2014). Most of the herbal ingredients are extracted in different solvents that may exert toxic effects. When traditional herbal formulations are administered, only a low amount of dose reaches to the site and rest of the drugs get wasted as it is distributed throughout the body depending on physicochemical and biochemical properties resulting in low therapeutic value. Another constraint of oral herbal formulations is that many ingredients of the herbal drugs may get deteriorated in the acidic $\mathrm{pH}$ of the stomach while some others may be metabolized in the liver so that inadequate amount of the phytopharmaceuticals may reach the blood (Yadav et al., 2011; Ansari et al., 2012). There would be either slow or no therapeutic effect if drug is not administered in the optimum quantity/ dose (minimum effective dose level). Some of the phytoconstituents derived from the natural origin have poor solubility and low bioavailability resulting in a narrow therapeutic index, thus scientists are working on drug targeting and controlled release of phytoconstituents to provide better therapeutic effect and increased patient compliance (Park, 2014).

The route of administration of the drug has a considerable impact on its effectiveness. A drug molecule needs to be given in an optimal concentration (dose) to achieve its therapeutic potential. If it is given in a smaller amount than optimal concentration, no therapeutic benefit is derived and at higher concentration, it could exhibit toxic effects (Charman et al., 1999). Due to the abovementioned constraints and poor efficacy of the treatment of relentless diseases, multidisciplinary approaches are envisaged for tissue-specific delivery of herbal therapeutics to enhance their pharmacokinetics, pharmacodynamics, bio-recognition, and efficacy. These novel delivery methods are based on interdisciplinary inputs of polymer chemistry, pharmacology, nanotechnology, bioconjugate chemistry, etc (Charman et al., 1999).

\section{Nano Delivery Systems for herbal drugs}

From past two decades, nanotechnology is exploited for efficacious drug delivery and tissue-specific targeting of drug (Kumar et al., 2015). Improved drug delivery techniques help in minimizing toxic effects and achieving enhanced effectiveness which is beneficial for the patients. Important attributes pertaining to herbal remedies could be improved component solubility, enhanced bioavailability, increased absorbency, reduced herbal doses, achieving steady-state therapeutic levels of drugs and overall better compliance (Ansari et al., 2012). Some of the strategies of drug delivery are employed to cross physical barriers, viz. blood-brain barrier (BBB) or on finding alternative suitable routes for drug delivery other than the oral delivery where drug constituents can be degraded (Kumar et al., 2015). At present "Novel Drug Delivery Systems" (NDDS) are exploited mainly for allopathic medicines. However, recent emphasis has been given to employing NDDS for safe, effective and time-tested 'ayurvedic' herbal drug formulation that could prove to be an attractive choice in the present scenario.

Delivery of pharmaceutical molecules is a process of administering it to the patient through suitable route to achieve a specific therapeutic effect. Common routes of drug delivery are per-oral (through the mouth), topical (skin), transmucosal (nasal, buccal, sublingual, vaginal, ocular and rectal) and inhalation routes. Modern phytopharmaceutical investigations can be exploited for development of NDDS based herbal drugs (Bhokare et al., 2016). NDDS includes various strategies for transporting a pharmaceutical molecule in the body to safely attain its desired curative effects which may either require its specific targeting or it might require systemic pharmacokinetics. In nutshell, NDDS are advance delivery approaches to enhance drug effectiveness by targeting the drug to the desired site, by controlling drug release to provide sustained curative effect and offer better safety (Nagavarma et al., 2012). NDDS includes carrier based drug delivery system (liposomes, niosomes, microspheres, resealed erythrocytes as drug carriers), trans-dermal Delivery Systems (sonophoresis), mucoadhesive delivery systems, supramolecular delivery systems and variable release delivery systems (osmotic pump, nanoencapsulation), etc. Due to the presence of diverse ingredients development of NDDS for herbal formulations is a challenging task (Nagavarma et al., 2012).

Nano herbal formulations can be employed for site-specific targeting of herbal medicines to enhance their selectivity, solubility, delivery, safety, and effectiveness. The nanosized drug increases their surface area thereby allowing quicker distribution in the blood and reduced toxicity while maintaining the therapeutic effects. The enhanced permeation and retention of nanoparticles (NPs) can also help to cross BBB (Kumar et al., 2015; Ganesan et al., 2017). Phyto-pharmaceuticals require a methodical strategy for efficient and sustained delivery to enhance patient acceptability and to prevent frequent drug administration. "Nano Delivery Systems" for herbal formulations can be employed for this purpose and combat limitations of herbal drugs. NDS help in enhancing therapeutic value and bioavailability and also decreasing frequent administration of herbal drugs 
(Govindarajan et al., 2017). Therefore, amalgamation of NDS in the traditional remedies is of vital importance for treatment of many chronic ailments like asthma, cancer, etc. (Aqil et al., 2013; Bonifácio et al., 2014; Sharma \& Singh, 2014; Gunasekaran et al., 2014; Mathur, 2016). Flavonoids have shown to exhibit poor stability, bioavailability, and bioefficacy if administered through oral route (Manach et al., 2005). Due to this constraint, various bioactivities attained in vitro conditions reveal either poor or no in vivo activities. Bilia et al. (2014b) reviewed the role of NDS like nanospheres, nanocapsules, micro- and nanoemulsions, micelles, solid lipid nanoparticles and nanostructured lipid capsules, for resolving shortcomings associated with the oral delivery of flavonoids. Flavonoids displayed improved stability and absorption when administered through NDS (Dube et al., 2010; Manjili et al., 2016). It is further reported that nano-based flavonoids possess enhanced surface area, better stability and bioavailability due to receptor-mediated phagocytosis and endocytosis by specific cells (Tan et al., 2012). NDS also mediate controlled discharge of encapsulated flavonoids. Bilia et al. (2014b) concluded in their review that nanocarriers made of approved molecules referred to as "Generally Recognized as Safe" (GRAS) may be used for development of efficacious preparations of herbal functional foods, dietary supplements, and therapeutics. Different types of nanosized herbal formulations can be prepared to achieve the enhanced therapeutic potential of phytomedicines (Table 1).

Table 1 Examples of different types of nanosized phytopharmaceuticals

\begin{tabular}{|c|c|c|c|}
\hline S. No. & Plant/ phytopharmaceuticals & Type of nano preparation & References \\
\hline 1. & Artemissia аппиа & Atrimisinin nanoparticles & Chen et al. (2009) \\
\hline 2. & Berberine & Berberine-loaded nano-particles & Lin et al. (2007) \\
\hline 3. & Centella asiatica & Nano-encapsulation & Kwon et al. (2012) \\
\hline 4. & Curcuma longa (Curcumin) & Micro-emulsion & Bist et al. (2007) \\
\hline 5. & Cuscuta chinensis & Nano-suspension & Yen et al. (2008) \\
\hline 6. & Lippia sidoides & Chitosan polymericnanoparticles & Bilia et al. (2014a) \\
\hline 7. & Origanum vulgare & chitosan polymeric nanoparticles & Hosseini et al. (2013) \\
\hline 8. & Picrohiza kurrooa & $\begin{array}{l}\text { pluronic-F- } 68 \text { copolymer based } \\
\text { biodegradeable PLA nanoparticles }\end{array}$ & Jia et al. (2015) \\
\hline 9. & Sophora japonica & Nanprecipitation & Wu et al. (2008) \\
\hline 10. & Silibinin & Solid lipid nanoparticles & Zhang et al. (2007) \\
\hline 11. & Curcuma longa & Curcumin phytosome & Maiti et al. (2007) \\
\hline 12. & Echinacea angustifolia & Phytosome & Kareparamban et al. (2012) \\
\hline 13. & Sophor a flavescens & Oxymatrine Liposome & Yue et al. (2010) \\
\hline 14. & Allium sativum & Garlicin liposome & Khan et al. (2007) \\
\hline 15 . & Capsicum аппиа & Capsaicin liposome & Mahajan et al. (2010) \\
\hline 16. & Curcuma longa & Curcumin Liposome & Dhule et al. (2012) \\
\hline 17. & Hibiscus dabdariffa (Flowers) & Liposome & Gibis et al. (2014) \\
\hline 18. & Magnolia officinalis & Magnolol Liposome & Chen \& Wu (2008) \\
\hline 19. & Scutellaria baicalensis (Wogonn liposome) & Liposome & Xue et al. (2007) \\
\hline 20. & Azadirachta indica (Leaves) & Emulsion & Xu et al. (2010) \\
\hline 21. & Carapa guianensis (Seeds) & Emulsion & Baldissera et al. (2013) \\
\hline 22 & Eucalyptus globules (Leaves) & Emulsion & Sugumar et al. (2014) \\
\hline
\end{tabular}




\begin{tabular}{|c|c|c|c|}
\hline S. No. & Plant/ phytopharmaceuticals & Type of nano preparation & References \\
\hline 23. & Curcuma longa (Zedoary turmeric oil) & Emulsion & Zhao et al. (2010) \\
\hline 24. & Capsicum annua (Capsaicin) & Transferosomes & Long et al. (2006) \\
\hline 25. & Colchicum autumnale (Cochicine) & Transferosomes & Singh et al. (2009) \\
\hline 26. & Curcuma longa (Curcumin) & Transferosomes & Patel et al. (2009) \\
\hline 27. & $\begin{array}{l}\text { Glycyrrhiza glabra (Amonium } \\
\text { glycyrrhizinate) }\end{array}$ & Ethosomes & Paolino et al. (2005) \\
\hline 28. & Podophyllum hexandrum (Podophyllotoxin) & Ethosomes & Yan et al. (2010) \\
\hline 29. & Sesbania grandiflora (Sesbania ethosome) & Ethosomes & Nirved et al. (2012) \\
\hline 30. & Sophora flavescens (Matrine ethosome) & Ethosomes & Zhaowu et al. (2009) \\
\hline 31. & Tripterygium wilfordi (Triptolide) & Ethosomes & Chen et al. (2012) \\
\hline 32. & $\begin{array}{l}\text { Curcuma longa (Curcumin floating } \\
\text { microspheres) }\end{array}$ & Microsome & Kumar \& Rai (2012) \\
\hline 33. & $\begin{array}{l}\text { Ruta gravelons (Rutin- } \\
\text { alginatemicrocapsules) }\end{array}$ & Microsome & Xiao et al. (2000) \\
\hline 34. & Sophora japonica (Quercetin) & Microsome & Chao et al. (2010) \\
\hline 35. & Camellia sinensis (Leaves) & Nanoemulsion & Gadkari \& Balaraman (2015) \\
\hline 36. & Podophyllotoxin & Solid lipid nanoparticles & Zhu et al.(2009) \\
\hline 37. & Triptolide from Tripterygium wilfordii & Solid lipid nanoparticles & Mei et al.(2003) \\
\hline 38. & $\begin{array}{l}\text { Diclofenacdiethylamine and curcumin } \\
\text { nanocarrier transdermal gel }\end{array}$ & Encapsulation with sonication & Chaudhary et al. (2014) \\
\hline 39. & AgNPs of Bauhinia tomentosa Lin & Nanosuspension & Mukundan et al. (2015) \\
\hline 40. & $\begin{array}{l}\text { Polymeric NP formulation } \\
\text { of Syzygiumcumini }\end{array}$ & Emulsification/evaporative solvent technique & Cargnelutti et al. (2016) \\
\hline 41. & Witepsol SLNPs and Carnauba SLNPs & Hot melt ultrasonication & Campos et al. (2015) \\
\hline 42. & $\begin{array}{l}\text { Oleanolic acid loaded PEGylated PLA and } \\
\text { PLGA NPs }\end{array}$ & $\begin{array}{l}\text { Ring opening polymerization followed by } \\
\text { nanoprecipitation method }\end{array}$ & Man et al. (2015) \\
\hline 43. & $\begin{array}{l}\text { Electrospun gelatin nanofibres } \\
\text { containing Centella asiatica extract }\end{array}$ & Electrospinning & Yao et al. (2017) \\
\hline
\end{tabular}

\subsection{Liquid Crystal}

Liquid crystal nanoparticles (LCNPs) are made through the miniemulsion method which is giving droplet size from 180 to $630 \mathrm{~nm}$ (Tongcher et al., 2006). LCNPs based pharmaceuticals are comprised of organic liquid crystal materials which are similar to natural bio-molecules like proteins, lipids, etc. These are supposed to be providing innocuous drug delivery system that can be employed for drug targeting to a particular part of the body where inflammation or tumors are present (Zhang et al., 2015c). From past some time, efforts are directed for developing selfemulsifying drug delivery system (SEDDS) for phytopharmaceuticals. SEDDS consist of oil, surfactant, cosurfactant and drug molecules which can spontaneously form isotropic and thermodynamically stable oil-in-water micro/ nanoemulsion once mixed along with water by moderate stirring Spillmann et al. (2014) produced a multifunctional LCNPs based delivery system for doxorubicin (anticancer drug) that showed proficient delivery of the carge drug. Such preparations may provide a sustainable approach due to their lipophilic nature in comparison to conventional herbal preparations to resolve constraints associated with traditional herbal drugs (Zhang et al., 2015c; Lai \& Rogach, 2017).

LCNPs can be used as effective method for targeted drug delivery, better bioavailability and drug stability. However, due to high cost and energy needs required for development of LCNPs based preparation cause hindrances to their extensive usage in the pharmaceutical industry. Lee et al. (2016) made LCNPs by employing a novel low energy procedure called phase-inversion 
temperature technique. LCNPs formulated by the said technique was found to be of about $100 \mathrm{~nm}$ dimensions which showed a lamellar liquid crystal assembly with orthorhombic lateral packing. Lee et al. (2016) reported five fold increase in bioavailability, liver-specific delivery and sustained release of the LCNPs based drug. Vicentini et al. (2008) described the physical, chemical and functional stability of LCNPs composed of vitamin E $d$-alpha-tocopheryl polyethylene glycol 1000 succinate, isopropyl myristate, $\mathrm{PG}-\mathrm{H}_{2} \mathrm{O}$ containing $1 \%$ quercetin maintain its lamellar phase.

Curcumin-loaded lipid cubic liquid crystalline nanoparticles were prepared and their physicochemical properties and oral absorption were evaluated and reported to be better for oral administration of curcumin as compared to only crude curcumin (He et al., 2015). Salmazi et al. (2015) reported curcumin-loaded liquid crystal precursor mucoadhesive system (LCPM) to be sixteen-folds more effective in case of a standard strain and two-folds more effective against a clinical strain of the pathogen as compared to free curcumin by conducting an in vitro antifungal assay against $C$. albicans. The outcome of the study showed LCPM to be an effective substitute for vaginal candidiasis therapeutics. Ramos et al. (2015) reported efficacious therapeutic action of Syngonanthus nitens (bong.) ruhland for the treatment of Candida krusei infection by carrying out various in vitro and in vivo analyses using LCPM based preparations.

\subsection{Liposomes}

Liposomes are lipid-based liquid crystals which are widely used in pharmaceutical and cosmetic industries due to their biocompatibility and ability to break down into the cells after delivering the loaded molecules (Dua et al., 2012). Liposomes were amongst the first engineered NPs employed for site-specific delivery of the drug. The major constraint of the liposome is that they have a tendency to fuse together in aqueous milieus which causes the release of loaded constituents. This has led to the development of alternative strategies for their replacement. Liposomes are the biodegradable, colloidal and sphere-shaped vesicles of about $0.05 \mu \mathrm{m}$ to $5.0 \mu \mathrm{m}$ in diameter. These are made of a hydrophobic bilayer membrane entrapping an aqueous core. The liposome may be made from naturally-derived phospholipids or of pure synthetic lipids with define acyl chains and head group (Laouini et al., 2012; More et al., 2016). Liposomes can be used to trap drugs having extensively different lipophilicities which can be loaded either in the phospholipids bilayer or entrapped in the aqueous core or at bilayer interface (González-Rodríguez \& Rabasco, 2011). Liposomal based drug delivery system has some benefits like it can enhance the therapeutic index of an anti-cancer agent (Sipai et al., 2012). Numerous liposome-based herbal preparations have been reported to exhibit improved efficacy due to enhanced solubility, bioavailability, specific site targeting and sustained drug release (Singh et al., 2009). Crielaard et al. (2012) showed that novel PEGylated colchicine-derived prodrugs can be retained inside the aqueous core after entrapment into liposomes in contrast to colchicine and usage of different biodegradable linkers can cause controlled release of the active parent. Another study showed improved solubility and permeability of crude soybean phospholipids based liposomes of ethanolic extract of Orthosiphon stamineus (Aisha et al., 2014).

\subsection{Transferosomes}

Phospholipid-based vesicles called as the 'transferosomes', are exploited mainly for transdermal delivery of the drug. Transferosomes can penetrate through the stratum corneum which have been a major constraint in case of dermal preparation that shows poor penetration due to hydration or osmotic force in the skin. Transfersomes based formulations are reported crossing through a wide range of pore sizes with the diameter ranging from $50 \mathrm{~nm}$ to $400 \mathrm{~nm}$ that depends on the initial transfersomes suspension (Venkatesh et al., 2014).Transferosomes formulations are composed of phospholipids that form a vesicle, surfactants to give flexibility, alcohol as a solvent and buffering agent to provide the hydrating medium (Lei et al., 2013; More et al., 2016). Xiao-Ying et al. (2006) prepared capsaicin transferosomes through high shear dispersion method and showed better skin penetration in comparison the pure drug as observed through the topical application. Transferosome based curcumin loaded topical gel preparation showed enhanced bioavailability and penetration through the skin (Patel et al., 2009). Transferosome based colchicine formulation was reported to combat gastrointestinal discomforts associated with oral administration of colchicine in gout treatment (Singh et al., 2009). Lecithin and sodium deoxycholate based transferosomes vincristine sulfate preparation has been shown to uphold zero order kinetics of the drug dispersal through the skin (Lu et al., 2005).

\subsection{Phytosomes}

Phytosomes are phytolipids based delivery with size ranging from $50 \mathrm{~nm}$ to a few hundred $\mu \mathrm{m}$ (Patel et al., 2013; Pawar \& Bhangale, 2015). Phytosome mediated delivery system is new promising approach exploited for phytopharmaceuticals which can be bound by lipids mainly lecithin. Phytosomes are miscible in an aqueous environment and possess lipophilic outer layer and thus exhibit enhanced absorption and bioavailability than the traditional herbal preparations (Pawar \& Bhangale, 2015; Kumar et al., 2017). Phytosomes possess better pharmacokinetic and pharmacological potential which makes them suitable therapeutics to be exploited for acute and chronic liver ailments and as dietary supplements. Herbal phytosomal preparations are readily absorbed, utilized and efficient as compared to traditional phytoformulations (Bhattacharya, 2009; Gandhi et al., 2012) and 
thus show better therapeutic effects and require less dosage to produce desirable effect (Hüsch et al., 2013; Jiang et al., 2013). Phosphatidylcholine (PC) is the key component of phytosome which has a dual function. PC can be used to load a cargo and display hepatoprotective potential (Karimi et al., 2015). Phytosomes have better stability than liposomes. Because of enhanced skin penetration phytosomes also improve skin absorption of phytoconstituents and thus are extensively exploited in cosmetics (Kalita et al., 2013). Phytoconstituent from phytosomes are rapidly eliminated (Sravanthi \& Krishna, 2013; Pawar \& Bhangale, 2015). Zhang et al. (2013) prepared curcumin phytosome-loaded chitosan microspheres (Cur-PS-CMs) by conjugating polymer and lipid-based delivery approaches.

\subsection{Ethosome}

The major constraint of oral administration of the drug is gastrointestinal hindrances which make transdermal drug delivery system (TDDS) to be an important alternative system. However, the main disadvantage of TDDS is that it has to traverse the barrier of the stratum corneum that allows passage of lipophilic molecules of > 500 Da molecular weight (Kumar et al., 2010; Dave et al., 2012). Variety of approaches has been explored, such as ionophoresis, sonophoresis, etc to enhance the penetration of drug molecules through the skin. Ethosomes are ethanolcontaining phospholipid vesicles or a novel liposome with size range from ten $\mathrm{nm}$ to microns, with high deformability and entrapment potential which can traverse through the skin and display better drug delivery in case of topical formulations (Paolino et al., 2005; Zhou et al., 2010; Celia et al., 2012; Vijayakumar et al., 2014). Ethosomes display far better transdermal flux as these can readily cross through the skin layers. It is biocompatible and can be used to load high molecular weight compounds (peptides, proteins, etc.). Ethosomes mediated delivery approach may be useful in cosmetics and human/ veterinary therapeutics due to better patient compliance. Ethosomal based delivery method is comparatively simple, passive, non-invasive approach that can be exploited at commercial scale quickly as compared to other delivery methods (Aggarwal \& Nautiyal, 2016). It offers slow and sustained drug release rather than fast drug release. However, the molecular size of the therapeutic compound should not be large for topical applications. The major drawback of ethosomal preparations is their cost factor and poor yield which make them uneconomical (Aggarwal \& Nautiyal, 2016).

Due to their physiochemical properties, ethosomal preparations can traverse through deeper skin layers into stratum corneum effectively and can also reach to the blood circulation. These aspects make them of immense important as a topical drug delivery vehicle and TDDS. Discharge of ethanol from the ethosomes is helpful in enhancing the fluidity of skin lipids which leads to improved skin penetration of the ehthosomal drug. Increased diffusion of ethosomal loaded drug is because of several reasons rather than due to the presence of simple hydroalcoholic solution in them (Dayan \& Touitou, 2000). Another important feature of ethosomal carriers is that both hydrophilic as well as for lipophilic cargos could be efficiently loaded for intracellular delivery (Fatima et al., 2014). Ethosomal preparations have carrier vesicles containing high amount of hydroalcoholic or hydro/alcoholic/glycolic phospholipids. Ethosomes facilitate passage of high amount of pharmaceutical constituents through transdermal route due to different types of constituent phospholipids (Yan et al., 2010; Pawar et al., 2015). Sustained drug release can be regulated by altering alcohol: water or alcohol-polyol: water ratio.

Maestrelli et al. (2009) evaluated the link between a method of preparation employed for ethosome preparation and its effect on their in vivo efficiency by taking benzocaine-loaded ethosomes. Chen et al. (2012) reported that ethanol and phospholipids ratio can affect drug loading efficiency of prepared ethosomes. Triptolide ethosomes displayed smaller nanoparticle size, uniform distribution and increased loading efficacy when prepared using $2 \%(\mathrm{w} / \mathrm{v})$ lecithin and 45\% ethanol (v/v). Chen et al. (2013) displayed the direct correlation between ethosomal size and ethanol/ phospholipids contents in case of curcumin loaded ethosomes. They further confirmed enhancement of percutaneous penetration and loading ability of curcumin ethosomes.

\subsection{Niosomess}

Niosomes are non-ionic vesicular preparations made through hydration of synthetic surfactants in which cholesterol or other lipids may or may not be included (Conacher et al., 2000). These could be employed for loading amphiphilic and lipophilic drug molecules and are like liposomes. In comparison to liposomes, these are found to be less costly and possess better stability. The salient constituents used for the preparation of niosomes are nonionic surfactants, hydration medium, and lipids such as cholesterol (Chandu et al., 2012). A closed bilayer vesicular structure gets self-assembled when nonionic surfactants are exposed to the aqueous environment due to great inter-facial tension amongst water and hydrophobic part of the amphiphilic molecules (Makeshwar \& Wasankar, 2013). Hydrophilic tail points towards aqueous environment because of steric and hydrophilic repulsion among the hydrophobic head groups of nonionic surfactant. There is energy requirement in form of mechanical or heat for the formation of such sealed bilayer structures (Lohumi et al., 2012). Niosomes are of three types based on the size and bilayers, 10-100 nm sized small unilamellar vesicles (SUV), 100-3000 nm sized large unilamellar vesicles (LUV) and multilamellar vesicles (MLV) made of more than one bilayer. 
The drug delivery mechanism of niosomes is similar to liposomes as these can also be used for sustained release of loaded drug and altering its organ distribution. Niosomal drug vehicles are stable, biocompatible, bio-decomposable, non-immunogenic, possess long shelf life and facilitate targetted drug delivery with a slow release of drug molecules (Balakrishnan et al., 2009). These could be exploited to attain better bioavailability in case of insufficient absorption of orally administered drugs and improved skin permeation in case of topical drugs. These also increase the therapeutic potential of loaded pharmaceutical molecules by causing slow clearance of drug molecules from the body, prevent degradation of drug in the biological system and slow release of drugs at targeted site (Moghassemi \& Hadjizadeh, 2014; Seleci et al., 2016). However, some of the problems associated with the niosomal preparations are the formation of aggregates by fusion, leakage and hydrolysis of entrapped drug molecules (Chandu et al., 2012). Nagalakshmi et al. (2016) reported the better efficacy of niosomal herbal gel over the plain herbal gel. Rahman et al. (2015b) successfully formulated curcumin-based niosomal transdermal gel as a possible candidate for anti-inflammation therapies. Un et al. (2015) prepared marigold extract loaded niosomal preparation and explored its usage employing cell culture system. Zingiber cassumunar Roxb.(ZC) extract entrapped niosomal gel preparation for topical application was described by Priprem et al. (2016) and reported it to be stable, efficacious and at par with therapeutic anti-inflammatory potential of steroid and NSAID.

\subsection{Solid Lipid Nanoparticles}

Salient constituents of Solid Lipid Nanoparticles (SLNs) are lipids along with surfactants used for emulsification that remains in solid state at room temperature, with size ranging from $50 \mathrm{~nm}$ to $1000 \mathrm{~nm}$ (Mukherjee et al., 2009). Large surface area of SLNs helps in enhancing drug packaging capacity. Overall small sized SLNs based delivery preparations display high-efficiency loading of pharmaceuticals, nutraceuticals and other materials (Chen et al., 2006). Transdermal, oral and parenteral delivery routes are used in case of pharmaceuticals (Mei et al., 2005). SLNs can be prepared by spray drying with shear mixing, ultra-sonication and high-pressure homogenization (Ekambaram et al., 2012). Several lipids like fatty acids, triglycerides, steroids, partial glycerides, and waxes are used for the preparation of SLNs along with various types of surfactants like soybean lecithin, phosphatidylcholine, poloxamer 188 , sodium cholate that are generally used as emulsifiers to stabilize lipid dispersion (Mukherjee et al., 2009).

Most important feature of SLNs is absence of organic solvents and use of physiological lipids for their preparation and thus SLNs are suitable for drug delivery vehicles through dermal, oral and intravenous routes. Some of the additional advantages of SLNs are degradation deterrence of delicate pharmaceutical molecules in aqueous milieu, better bioavailability, enhanced stability, sitedirected sustained release of pharmaceuticals, ability to load lipophilic as well as hydrophilic molecules, ease of degradability of constituent biological lipids and non-toxic nature (Dwivedi et al., 2014). Due to improved stability in comparison to liposomes, SLNs could easily be exploited for commercial fabrication of various site targeted colloidal drug delivery vehicles that could be stable for a minimum of one year. Zhang et al. (2013) reported incorporation of Triptolide (TP) into SLNs by microemulsion technique. TP-SLNs showed comparatively greater entrapment efficacy, better stability in an artificially created gastric environment and sustained release in vitro. Additionally, SLNs have shown the potential of evading irritation of gastric mucosa because of reduced lipid peroxidation and inflammation which occurs when TP is given in rats orally (Zhang et al., 2013). Kaempferia parviflora (KP) extracts loaded SLNs displayed better transdermal penetrability. The flux values of three of the flavonoids studied were found to be greater when incorporated in SLNs (Sutthanut et al., 2009).

Solid state nanoparticles prepared by blending solid and liquid lipids. Nanostructured Lipid Carriers (NLCs) are flexible in nature and thus could be exploited for the production of varied types of solid matrices for attaining better drug molecules loading capacity, for example, NLCs and lipid drug conjugate nanoparticles (LDCs). NLCs are prepared through solidified emulsion (dispersed phase) based method. Entrapped pharmaceutical molecules are slowly released due to a gradual degradation of lipids inside the body and disperse by diffusion (Zhao et al., 2010; Want et al., 2015). Because of extremely unordered lipid structures, more amount of drug can be loaded in NLCs. If needed, a quick unloading of drug molecules could be prompted by applying the trigger impulse to the matrix and alter it into an ordered structure. Shi et al. (2012) reported the formation of frankincense and myrrh oil loaded SLNs. Jourghanian et al. (2016) showed sustained release of curcumin due to hydrogen bonding between cholesterol and curcumin in curcumin loaded SLNs. Lipid structure of cholesterol causes enhanced permeability in studied bacteria to increase antibacterial characteristics of curcumin and concluded that the designed curcumin SLNs could be a likely candidate for the formulation of different dosage forms or cosmeceutical products. Arora et al. (2015) found the ameliorating effect of curcumin loaded SLNs against adjuvantinduced arthritis in rats.

\subsection{Metal Nanoparticles based drug delivery}

Various metal nanoparticles (MNPs) based herbal formulations are reported to be better and efficacious. "Ayurveda" is a primeval Indian health care system based on medicinal plants and herbo- 
mineral preparations. Biologically prepared metal nanoparticles known as "Bhasma" are used for the treatment of various diseases/ disorders in Ayurveda (Pal et al., 2014). Nano forms of seven metals are generally utilized in Ayurveda: gold $(\mathrm{Au})$, silver $(\mathrm{Ag})$, copper $(\mathrm{Cu})$, iron $(\mathrm{Fe})$, lead $(\mathrm{Pb})$, tin $(\mathrm{Sn})$ and zinc $(\mathrm{Zn})$. Applications of this old system are being rediscovered and could be of immense potential in yielding innovative metal-herb formulations that could be an interesting idea in biomedicine (Galib et al., 2011). For developing such preparations, biocompatibility and therapeutic activity of phytoconstituents present in plants a determinative role in choosing various herbs. Such herbo-mineral preparations could have better curative potential because of their physiological compatibility, meager toxicity, natural origin, easy accessibility and being less costly. Tremendous applications of such nanomaterials based herbal preparations in the field of biomedicine have led to an innovative concept of 'Herbo-nanoceuticals' (Gomes et al., 2014).

Many studies have shown that during the processing of ayurvedic metal based formulations, size of the metal particles come down to nanometer range (Pavani et al., 2013). Gold is used as Swarna Bhasma (gold ash) in different conventional Indian ayurvedic preparations and has been characterized to possess 56$57 \mathrm{~nm}$ size and spherical shape. Mercury-based ayurvedic preparations have crystalline mercuric sulfide of $25-50 \mathrm{~nm}$ size range (Pal et al., 2014). Pavani et al. (2013) reported a modified method of 'bhasmikaran' (method of preparing bhasmas) for preparation of iron oxide nanoparticles which was based on green synthesis. X-ray diffraction and transmission electron microscopy (TEM) analyses demonstrated that during ayurvedic 'bhasmikaran' method metal NPs are formed. The metal NPs along with various phytoconstituents can lead to better absorption and even tissue-specific targeting of therapeutic ingredients inside the body. Because of their small size, these preparations are said to be more effective as the naturally synthesized metal NPs do not cause toxicity in the body (Paul \& Chugh, 2011).

Green synthesis of MNPs could be carried out by utilizing many natural compounds viz. vitamins, carbohydrates (sugars), phytochemicals present in plant extracts, microbes, biodegradable polymers etc. Plant extracts are used for the commercial preparation of MNPs because of the presence of phytoconstituents that are amongst potent reducing agents (Iravani, 2011; Shah et al., 2015). Polyphenols are the main phytoconstituents in plant extracts that possess the ability to act as reducing agent mainly because of their hydroxyl side chains. These can act as capping and stabilizing agents for MNPs formation. Gold ( $\mathrm{Au}$ ) NPs are amongst the most widely utilized MNPs in biomedical field because of their biocompatibility (Bhattacharya \& Mukherjee, 2008). Geetha et al. (2013) reported a quick, economical and single-step method for formation of AuNPs by utilizing flower extract of Couroupita guianensis. Green synthesis of AuNPs was stated using glucoxylans of Mimosa pudica seeds in which no extra chemical stabilizing agent was added (Iram et al., 2014). Rao et al. (2016) discussed different medicinal plants and their active compounds, as well as green-synthesized metallic NPs from medicinal plants in relation to their anticancer activities. MNPs formed using plant extracts showed enhanced tumor specificity, promising activity and reduced toxic effects to healthy cells. The cytotoxic effects of NPs are predominantly due to their large surface area, which enables efficient drug delivery and some NPs exhibit anticancer activity. However, further in vivo studies should be conducted to confirm the actual efficacy of herbal NPs based drugs (Rao et al., 2016). MNPs included quantum dots, metal oxides and pure metal NPs that are said to be useful in various biomedical applications (Bonifácio et al., 2014; Sharma \& Singh, 2014; Ambwani et al., 2015). Many researchers have put forward various methods for green synthesis of MNPs employing microorganisms and plant extracts that are found to be ecofriendly, economical and non-toxic (Makarov et al., 2014). However, there are certain problems with MNPs which needs to be addressed before there commercial usage. Though MNPs used for various purposes are reported to possess diverse characteristics, diverse derivation and are being utilized in various systems. However, their potential side effects in the patients and environment are yet to be thoroughly explored (Krug \& Wick, 2011). Contradictory biosafety considerations are reported pertaining to MNPs in different studies (Tsoi et al., 2012; Edmundson et al., 2014; Ambwani et al., 2015).

\subsection{Nanoshells}

Nanoshells are popularly known as core-shells which are few nanometer (1-20 nm) in size. These have sphere-shaped cores (concentric particles) made up of a specific compound which is surrounded by an outer coating or shell made up of a different compound (Kalele et al., 2006). The properties of these core shells can be altered by changing core-to-shell ratio or constituent compounds of nanoshells. Core shells may be prepared by using semiconductor materials, metals or insulators. Because of the high stability dielectric compounds like silica and polystyrene are typically used to prepare cores (Ansari et al., 2012; Sachan \& Gupta, 2015). A new category of sphere shaped composite metal nanoshells is prepared in which core is of a dielectric material that is surrounded by a thin metallic shell usually made of gold. Nanoshells have immense applications in the biomedical field especially in drug delivery and in vivo imaging-based diagnostic approaches because of their unique optical and chemical properties. Nanoshells can absorb heat and allow its transmission to the local environment when it is illuminated by a suitable wavelength which leads to discharge of the cargo drug by 
breaking down the core-shell assembly (Kalele et al., 2006). In nanoshell based drug delivery systems, drug molecules can be encapsulated by the shell as well as can be adsorbed on the surface of the shell with the help of specific functional group or could be stabilized by electrostatic bonding (Krausz et al., 2015). When these drug-loaded nanoshells come in contact with the biological system, they release the drug. For tissue-specific drug targeting and in vivo diagnostic (imaging) approaches, specific antibodies against diseased tissues or tumors may be tagged with nanoshells which allow these core shells to provide an efficacious system for cancer diagnostics as well as therapeutics (Mamillapalli et al., 2016; Singhana et al., 2014).

Gold nanoshells (AuNSs) are presently being explored as targeted nanovehicles for loading drug which could be utilized for either diagnosis or therapeutic purposes. These have great potential in the field of oncology including photothermal ablation, hyperthermia, drug delivery and diagnostic imaging. AuNSs are of immense importance because of their bioacceptability, nontoxicity, surface plasmon resonance, insignificant immunogenicity and surface functionalization. AuNSs can be employed for tissuespecific drug unloading in precise amounts exclusively in the target cells after irradiated with near-infrared (NIR) laser. Singhana et al. (2014) made a comprehensive investigation of NIR activated AuNSs based drug delivery systems and cancer theranostics. AuNSs complexes are demonstrated to provide an effective drug delivery approach through which antitumor drugs (e.g., doxorubicin, paclitaxel, small interfering RNA, and singlestranded DNA) can be unloaded into the specified cancer cells. AuNSs can also be tagged with tissue-specific ligands such as antibodies, aptamers, and peptides to target these drug-loaded NPs to the desired tissues (Singhana et al., 2014).

\subsection{Quantum Dots (QDs)}

These are made of nanosized (2-10nm) semiconductors materials popularly called as nanocrystals that can emit light in all the colors of a rainbow depending on their size. These nanocrystals restrain transmission band electrons, valence band holes or excitations in 3-D directions. Salient QDs are semi-conductor and core-shell nanocrystals, in which interface of various semiconductor constituents is present. QDs are coupled with specific molecules capable of identifying the explicit tissues.

Such surface alterations can avert aggregate formation, decrease in non-specific attachment and are important for specific tissue targeting in case of in vivo diagnostic (imaging) approaches. Functionalization of QDs may be attained through modifying protecting ligands (Mulder et al., 2009), adding targeting groups viz. apolipoproteins and peptides. Near-IR QDs with polymer coatings that are tagged with an antibody against cancer cells are amongst the common QDs employed for tumor-targeting.
Development in this area is being appraised by many researchers (Papagiannaros et al., 2010). The surface modification of QDs for various bio-applications has been studied through the development of QDs for a specific purpose (Juzenas et al., 2008). Singh et al. (2017) reported curcumin QDs mediated degradation of bacterial biofilms.

Applications of QDs in photodynamic and radiation therapies for cancer have been reviewed extensively (Tan \& Zhang, 2005). Zhao et al. (2014) reported the synthesis of betaCyclodextrin/glycyrrhizic acid functionalized QDs that can specifically go into hepatic cells and prompt programme cell death in them. QDs may provide a structural scaffold in such a way that the imaging contrast agent and small-sized lipophilic drug molecules can be entrenched amid the inorganic core and the amphiphilic polymer coating layer. Tissue-specific molecules like antibodies, peptides, and aptamers which are used for targeting delivery vehicle and hydrophilic therapeutic molecules like small interfering RNA (siRNA) and antisense oligodeoxynucleotide (ODN) may be attached with the help of covalent or non-covalent binding onto the hydrophilic face of amphiphilic polymer. Such nanocomposites act like magic bullets, which can specifically identify and then bind to target diseased cells/ tissues and cure it by releasing therapeutics on the site. These nano delivery vehicles will also produce noticeable signals through which their movement inside the body could be monitored continuously in real-time.This property makes QDs suitable for in vivo imaging, localization of metastasis and cancer diagnostics (Ambwani et al., 2015; Belletti et al., 2017). Belletti et al. (2017) described the single-emulsion process for curcumin loading into NPs with encapsulation efficiency about $35 \%$. Post-formulation strategy to coat the surface of the curcumin-loaded NPs with QDs as imaging agents were applied obtaining tools useful for possible application in theranostic approach.

\subsection{Superparamagnetic Nanoparticle (SPION)}

Superparamagnetic molecules are responding to magnetic force but do not hold residual magnetism after withdrawal of magnetic force. Iron oxide NPs of 5-100 nm size range are being utilized for bio-separations based on selective magnetic properties (Wahajuddin \& Arora, 2012). For specific targeting usually, monoclonal antibodies against unique cell surface molecules are coated on the superparamagnetic iron oxide nanoparticles (SPIONs) so as to separate it from the milieu. SPIONs are exploited for targeted delivery of therapeutic molecules and gene transfection studies (Mcbain et al., 2008) which occurs due to the applied magnetic force that is used to accelerate and control their movement towards the specific site. These can be utilized as contrasting molecules in magnetic resonance imaging (MRI) because of their paramagnetic potential these can be visualized in MRI and may be directed towards a specific site by applying 
magnetic force. Further, these can be incited to unload cargo drug by heating it through applying a magnetic field (Dilnawaz et al., 2010). SPIONs are inorganic NPs which have a core of iron oxide. This core can be coated by inorganic compounds like silica, gold as well as by organic compounds like lipids, carbohydrates, oligopeptides, etc. SPIONs are of enormous importance for different theranostic applications (Ebrahimnezhad et al., 2013; Kumbhani et al., 2016).

SPIONs can be exploited for the development of MRI contrast improvement, tissue/ cell-specific drug delivery and hyperthermia in managing malignancy conditions. Dilnawaz et al. (2010) prepared glycerol monooleate based hydrophilic magnetic nanoparticles (GMO-MNPs) that could be used for targeting the anticancer drugs like paclitaxel, rapamycin, either alone or in the mixture, towards the specific tissue. Prepared GMO-MNPs displayed increased penetration of anticancer therapeutic molecules in case of human breast carcinoma cell line (MCF-7). Dorniani et al. (2012) synthesized nano-delivery vehicle with iron oxide-chitosan-gallic acid (FCG) for gallic acid transportation in the body. FCG NPs were non-toxic for normal human fibroblast (3T3) cell line, but they showed their toxicity against human breast cancer cell line MCF-7. Ebrahimnezhad et al. (2013) prepared silibinin-incorporated $\mathrm{PLGA}-\mathrm{PEG}-\mathrm{Fe}_{3} \mathrm{O}_{4} \mathrm{NPs}$ that displayed significant inhibitory effect on hTERT gene expression in T47D breast cancer cell line. Still, certain modes of action of SPIONs are not clear like how multifunctional SPIONs uptake occurs in human cells in vitro conditions; how SPIONs are adsorbed in sub-cellular compartments after their specific uptake by cells and transportation of various therapeutic molecules, vector DNA or other compounds to target site and their sustained discharge; deterrence of agglomeration of tailored SPIONs in physiological fluids and how SPIONs are causing their short-term and longer lasting effects on cells (Ebrahimnezhad et al., 2013; Kumbhani et al., 2016).

\subsection{Fullerene}

Fullerenes can be hollow globular, ellipsoidal or cylindrical shaped structures completely made up of carbon. Globular fullerenes are known as buckyballs while the tubular fullerenes are known as buckytubes or carbon nanotubes (Cha et al., 2013). Fullerenes have structural similarity with graphite that is made up of connected hexagonal rings of stacked graphene sheets. These can also be made up of pentagonal or even heptagonal rings that produce comparatively porous structures. Buckyballs also called Buckminster fullerenes or fullerenes are hollow, sphere-shaped configurations composed of sixty carbon atoms with a width of approximately $1 \mathrm{~nm}$ (Bakry et al., 2007).

Buckyballs can act as a relatively non-toxic vehicle for therapeutically important molecules because of their hydrophobic core that can retain hydrophilic compounds and nonpolar covalent interactions which do not allow electrovalent bonding with molecules (Xu \& Chen, 2013). Endohedral fullerenes are buckyball clusters or buckyballs made up of $<300$ carbon atoms. Carbon Mega tubes have a bigger width as compared to carbon nanotubes which could possess walls of varying breadth that could be employed for transportation of various molecules of diverse dimensions (Tripathi et al., 2015). C60-paclitaxel conjugated modified lipophilic fullerenes exhibited considerable anticancer potential with sustained C60-paclitaxel release ability in cell culture studies. Moreover, fullerenes have demonstrated the ability to pass through intact skin which could be an advantageous property for their usefulness in development of cellular targeting of drug molecules as well as in transfection approaches (Zhang et al., 2015a; Zhang et al., 2015b)

Naghsh (2015) investigated potential anti-inflammatory and anticancer effects of ginger extract including gingerol and shogaol with nanotubeas as drug delivery technique. Conium is an anticancer drug composed of piperidine alkaloids which were tagged with fullerenes C60 to alter its properties. Zabolotnyi et al. (2012) performed IR spectral analysis of the mixture of Conium and fullerene in the water solution which displayed the presence of a composite of fullerene with $\gamma$-coniceine alkaloid.

\subsection{Polymeric Nanoparticles based drug delivery}

Polymeric NPs include both nano-spheres as well as nanocapsules of $10-200 \mathrm{~nm}$ in dimensions that are in the solid phase and could either be amorphous or crystalline. These could be used to either adsorb and/or entrap therapeutically important molecules, or further prevent chemical and enzymatic denaturation of drug molecules. Natural or synthetic polymers can be used for designing nanocarriers that can be employed as drug delivery vehicles (Nagavarma et al., 2012). Some of the common natural polymers used for the synthesis of polymeric NPs are chitosan, gelatin, sodium alginate, albumin, etc. Large number of synthetic polymers like, Polyglycolides, Polyglutamic acid, Polyorthoesters, Polycaprolactone, Polycyanoacrylates, Polylactides, Polymalic acid, Polyvinylpyrrolidone, Polymethyl methacrylate, Polyvinylalcohol, Polyacrylamide, Polyanhydrides, Polyethylene glycol, Polymethacrylic acid, etc., can be used for development of polymeric NPs (Nagavarma et al., 2012). Recently, biocompatible polymeric NPs have received wide consideration in the development of sustained drug delivery approaches with a potential to be targeted towards a specific tissue inside the body (Conte et al., 2017). Costa et al. (2013) prepared chitosan-based polymeric NPs template for delivery of Barbatimão standardized fraction. These polymeric NPs were synthesized through ionotropic gelation technique in which two aqueous phases 
were mixed at room temperature. Liu et al. (2005) prepared triptolide based polylactic acid NPs that were found to be of sphere shaped, even surfaced and homogeneous dimension. Triptolide can produce toxic effects and have little solubility in the biological system. However, triptolide based polylactic acid NPs displayed their biocompatibility and biodegradability (Liu et al., 2005).

Sahu et al. (2008) designed a biocompatible curcumin loaded methoxy poly (ethylene glycol)-palmitate based polymeric NPs for cancer treatment. Min et al. (2008) reported that camptothecin incorporated lipophilic tailored glycol chitosan NPs possess increased stability and can be used for tumor cell-specific targeting. Yen et al. (2008) synthesized Cuscuta chinensis NPs through a nanosuspension technique that displayed better uptake of quercetin. Green tea (Camellia sinensis) aqueous extract is rich in catechins, especially epigallocatechin-3-gallate, epigallocatechin, epicatechin-3-gallate, and epicatechin. Generally recognized by its antioxidant activity, the green tea extract was associated with alginate and poly epsilon-caprolactone (PECL) nanoparticles. As expected, low entrapment of the active compounds, expressed by terms of epigallocatechin-3-gallate and epicatechin-3-gallate, was found (around 30\%). Nevertheless, the association of catechins to the polymeric matrix could modulate their release where $25 \%$ was found after $2 \mathrm{hrs}$ in comparison to nearly $100 \%$ release from free extract (Sanna et al., 2015).

\subsection{Nanospheres and Nanocapsules}

Biocompatible and recyclable polymers could be used for the preparation of polymeric nanoparticles (PNPs) of about 10-1000 $\mathrm{nm}$ size range. These PNPs can be utilized for dissolving, entrapping, encapsulating or surface binding of pharmaceutically important molecules. Spherical and capsular nanostructures can be prepared by employing various methods of PNPs preparations. Nanocapsular matrix made up of polymer membrane can be used to incorporate pharmaceutical compounds in its hollow cavity. Pharmaceutical compounds are evenly distributed in case of sphere shaped PNPs (Landfester et al., 2010). PNPs are gaining wide attention in various fields like electronics, photonics, conductors, sensors, medicine, biotechnology and environmental technology. These could be categorized into two groups depending upon whether synthetic or natural polymers are used for their preparation (Nagavarma et al., 2012). Nowadays PNPs are considered as important drug carrier matrices because of ease of loading drug molecules in them, targeting these to a specific site with overall better drug stability and safety (Lertsutthiwong et al., 2008). PNPs can be used for loading pharmaceutics, proteins, and DNA molecules efficiently and their delivery to specific site. Due to their nanostructure, these can easily penetrate across plasma membranes and quite stable in biological fluids like blood (Sharma et al., 2016). Natural and synthetic polymers can be molded into wide and diverse molecular designs that are used for making nanosized constructs having possible biomedical utility (Watnasirichaikul et al., 2000; Bisht et al., 2007).

Form past twenty years numerous techniques have been evolved for the synthesis of PNPs following either bottom up or top down approaches (Guterres et al., 2007). These PNPs can be made to alter the in vivo mode of action of the molecules, their sustained discharge, targeted tissue distribution, pharmacokinetic properties, and interaction with cell/ cellular components (Sharma \& Singh, 2014). PNPs can be designed to have various types of nano-scale structures like solid or hollow sphere shaped, tubular, porous or solid particles, branched structure, etc. Different substances and fabrication methods are used to achieve such nanostructures. Molecular self-assembly, bio-aggregation, nano-manipulation, photochemical patterning, molecular imprinting, layer-by-layer electrostatic deposition and vapor deposition techniques are employed to achieve nano-sized structures (Nagavarma et al., 2012; Sharma \& Singh, 2014). Bagheri et al. (2013) prepared whey protein nanocapsules with pit extract of date palm. Spigno et al. (2013) reported Vitis vinifera extract and hazelnut paste based nanocapsule preparation which showed enhanced solubility and antioxidative potential. Esmaeili \& Ebrahimzadeh (2015) prepared Aloe vera loaded polyamide nanocapsules for development of the efficacious delivery system. Aloe vera extract nanocapsules in the process of healing of burn wounds in mice showed that Aloe vera increased the healing rate of burns in mice. Several plant extracts based nanocapsule preparations were reported for better stability and delivery (Esmaeili \& Niknam, 2013; Rahman et al., 2015a)

\subsection{Dendrimers}

Dendrimers are becoming quite popular in the field of biomedicine. These are branched structures with several molecular 'hooks' on the surface that may be tagged with fluorescent dyes, enzymes and other molecules used for specific cell/ tissue targetting. Though dendrimers were prepared long ago, however, they have become popular recently after finding out their potential usefulness in nanomedicine and biotechnology (Wagner, 2007). Dendrimers can be modified without much difficulty because of the presence of many functional groups, possess a compact molecular structure and are similar to biomolecules like proteins, enzymes, and viruses. Drug molecules can either be coupled to the surface or incorporated inside dendrimers (Patel \& Patel, 2013). Recently some of these nanoforms, like polyamidoamine dendrimers can be utilized as possible blood alternative. One of the most important applications of dendrimers is their capacity for the targeted and slow release of drug molecules. Cancer theranostics is amongst the most challenging tasks in front of scientists in the current scenario. Improvement in pharmacokinetic attributes in cancer therapeutic 
drugs gaining a lot of attention and new strategies are envisaged to overcome problems associated with them. Drugs coupled with polymeric nanostructures have shown increased half-life, better stability and miscibility in an aqueous environment, little immunogenicity, etc (Kaminskas et al., 2011). Antitumor drug coupled with dendrimer have exhibited less systemic toxicity, enhanced solubility and selective accumulation in solid tumors. Therapeutic compounds, nucleic acids, specific tissue/ celltargeting molecules and dyes may be loaded in dendrimers by various approaches viz. encapsulation, complexation or conjugation.

Dendrimers possess branched structure made up of synthetic polymers, sphere shaped with a central core inside which is enclosed by cyclic layers and the outermost layer have various functional groups (Wijagkanalan et al., 2011; Kannan et al., 2012). Precisely controlled structural design of dendrimers with multiple functional groups present on the surface allows their chemical manipulation as carriers of multi-target inhibitors (MTIs) and also as imaging nanostructure. These surface modifications lead to alteration in the size, shape, density, chemical, optical attributes, etc (Hourani \& Kakkar, 2010).

Dendrimers can be tagged with specific antibodies or ligands for their site-specific targeting especially as nanocarriers for anticancer therapeutic drugs (Wani et al., 2015). Madaan et al. (2016) investigated the efficacy of quercetin-loaded polyamidoamine
(PAMAM) dendrimers for oral administration and stated them to be beneficial in resolving drawbacks of oral administration of quercetin. Camptothecin is an alkaloid that possesses significant anticancer potential which can be purified from Camptotheca acuminata. Zolotarskaya et al. (2015) reported the 'click synthesis' of a new camptothecin (CPT) prodrug based on anionic PAMAM dendrimer intended for cancer therapy. Conjugated CPT resulted in $\mathrm{G}_{2} / \mathrm{M}$ arrest and cell death while the dendrimer itself had little to no toxicity. Altogether, highly efficient 'click chemistry' allows for the synthesis of multifunctional dendrimers for sustained drug delivery.

Nowadays phytotherapeutics is obtained in nanoparticle form for improvement of their pharmacokinetic and pharmacodynamic profile (Ansari et al., 2012). The nanonization of phytopharmaceuticals displayed increased surface area to volume ratio, improved stability, solubility and bioavailability, reticuloendothelial system (RES) uptake, better penetrability and retention, site-specific targeting, controlled release, etc (Goyal et al., 2011). Numerous patents also have been sought to reap the aforesaid benefits (Table 2). In the last decade, a gradual increase in patents filed on herbal nanoformulations has been noted (Jadhav et al., 2014). The reason mainly lies in addressing the solubility and bioavailability problems of phytoceuticals. Curcumin, the multifunctional phytopharmaceutical, has especially been patented maximally and is used in the treatment of tumors and cancers.

Table 2 Some of the patents related to nanosized herbal preparations

\begin{tabular}{|c|c|c|}
\hline S. No. & Plants/ Phytopharaceuticals & Patents \\
\hline 1. & Curcumin - Nanoparticles & $\begin{array}{l}\text { Kurzrock R, Li L, Mehata K, Aggarawal BB (2011) Liposomal curcumin } \\
\text { fortreatment of cancer. US Patent } 007968115 \text { B2, 28 June } 2011 . \\
\text { Sahoo SK, Mohanty C (2011) Novel water soluble curcumin } \\
\text { loadednanoparticulate system for cancer therapy. WO Patent } \\
\text { 2011101859A1, 25 August 2011. } \\
\text { DiMauro TM (2013) Methylated curcumin-resveratrol hybrid molecules } \\
\text { for treating cancer. US Patent 008350093 B2, 8 January 2013. }\end{array}$ \\
\hline 2. & Carotenoids - Nanoparticles & $\begin{array}{l}\text { Matuschek M, Ernst A, Köpsel C, Jager MB, Kleber A, Krohn M et al. } \\
\text { (2010) Useof water-dispersible carotenoid nanoparticles as taste } \\
\text { modulators, tastemodulators containing water-dispersible carotenoid } \\
\text { nanoparticles, andmethod for test modulation.US Patent } 20100028444 \\
\text { A1, 4 February } 2010 .\end{array}$ \\
\hline 3. & Silymarin - Nanoparticles & $\begin{array}{l}\text { Xu X, Yu J, Tong S, Zhu Y, and Cao X (2011) Formulation of silymarin } \\
\text { with highefficacy and prolonged action and the preparation method } \\
\text { thereof. USPatent } 20110201680 \text { A1, } 18 \text { August } 2011 \text {. }\end{array}$ \\
\hline 4. & Vinca alkaloids - Nanoparticles & $\begin{array}{l}\text { Liang W, Lou M, Si W (2009) Nano anticancer micelles of vinca } \\
\text { alkaloidsentrapped in polyethylene glycolated phospolipids. US } \\
\text { Patent20090053293 A1, 26 February } 2009 . \\
\text { Zale SE, Troiana G, Ali MM, Hrkach J, Wright J (2010) Therapeutic } \\
\text { polymericnanopartcles comprising vinca alkaloids and methods of } \\
\text { making andusing them. US Patent } 20100104655 \text { A1, } 29 \text { April } 2010 .\end{array}$ \\
\hline
\end{tabular}

Journal of Experimental Biology and Agriculture Science http://www.jebas.org 


\section{S. No. Plants/ Phytopharaceuticals \\ Patents}

5. Gymnema sylvestre extract - Nanoemulsion

$>\quad$ Nanbu T (2009) Whitening cosmetic composition containing arbutinnanoparticles. US Patent 20090069253 A1, 12 March 2009

6. Withania somnifera - Liquid mixture

$>\quad$ Lillard JW, Singh R, Singh S (2007) Novel nanoparticles for delivery of activeagents. US Patent 20070224280 A1, 27 September 2007.

7. Curcuma longa - Nanoparticles

$>\quad$ Chole GM, Frautschy SA (2007) Bioavailable curcuminoids formulations fortreating Alzheimer's disease and other age-related disorders. WO Patent2007103435 A2, September 132007.

$>\quad$ Jacob CV (2012) Synergistic composition for enhancing bioavaliability ofcurcumin. US Patent 20120058208 A1, 8 March 2012 .

8. Lemon juice, Lepidium sativum -

> Chaudhary M, Naithani V (2011) Topical herbal formulation for Nanoemulsion treatment of acne and skin disorder. US Patent 20110262499 A1, 27 October 2011.

9. Arbutin - Emulsified nanoparticle

$>\quad$ Nanbu T (2009) Whitening cosmetic composition containing arbutinnanoparticles. US Patent 20090069253 A1, 12 March 2009.

10. Citrus and cinnamon - Solid nanoparticle dispersion

$>\quad$ Spengler EG, Dahms GH (2006) Composition and method employingmembrane structured solid nanoparticles for enhanced delivery of oralcare actives. US Patent 20060024248 A1, 2 February 2006.

11. Vitamin, herb - Bioadhesive nanoparticulate

$>\quad$ Wertz CF, Ryde NP (2008) Nanoparticulate compositions having lysozyme asa surface stabilizer. US Patent 007459283 B2, 2 December 2008.

12. Cucumis sativus - Nanoparticle

$>$ Gogerddan P, Ceredigion A (2013) Anti-inflammatory compounds. WIPO PatentWO2013054070 18 April 2013.

13. Novel antidiabetic herbal formulation

$>\quad$ Pushpangadan P, Rao C, Rawat A, Kumar D (2007) US Patent (US 20070042062 A1), 2007.

14. Herbal composition to relieve pain

$>\quad$ Kelly GJ, Perry A (2001) Herbal composition to relieve pain. US Patent (US 6312736 B1), 2001.

15. Herbal supplements and methods of use thereof.

$>$ Brown K, Scott BM (2014) US Patent (US 20140141108 A1), 2014.

16. Neem oil microemulsion without cosurfactants or alcohols and a process to form the same.

17. Transdermal delivery system for alkaloids of aconitum species

18. Sustainedreleasemicrogranules containing gingko biloba extract and the process for manufacturing these.

$>\quad$ Parmar BS, Varshney M, Shah DO (2014) US Patent (US 6703034 B2), 2014.

$>\quad$ Xiong W, Patel D (2004) US Patent (WO 2005034923 A1), 2004

$>\quad$ Marechal D, Yang WH, Hu YZ (2005) US Patent (US 20050042271A1), 2005.

\section{Biosafety of Nanosized herbal formulations}

Even though nanocarrier based herbal pharmaceutical preparations have shown their preeminence by counteracting inadequacies of conventional herbal formulations, their safety should not be ignored (Ambwani et al., 2015). For harnessing the probable advantages of nanotechnology in the field of biomedicine there is need to preclude the possibility of any unwanted toxicity to human/ environment and after ensuring their safety. In case of herbal formulations, nano delivery approaches can be fruitful in improving therapeutic ratio or index thereby enhancing the gap between dose required for their curative effects 
and minimum toxic level dose that gives unwanted side effects. In spite of this, there is a need for careful and elaborate toxicological examination of various nano deliveries based herbal formulations. The alteration in the physical, chemical, optical, structural attributes of engineered nanomaterials may lead to numerous predicted interactions with various biological constituents which can cause toxic side effects (Chan et al., 2010).

At present, it must be accepted that still there is a paucity of elaborate and methodical toxicological profiling of nanomaterials and nanomedicines, with insufficient data on safety and toxicity is available. Voigt et al. (2014) reported Polybutylcyanoacrylate NPs were found to be non-toxic and thus could be useful in the field of nanomedicine. Sadat et al. (2016) gave a concise summary of the alterations in various attributes of PNPs due to a different size and surface charge and what problems could arise during in vivo experimentations. Some studies have been conducted to exhibit either in vitro or in vivo toxic effects of various NPs (Wang et al., 2013; Ambwani et al., 2016; Datta et al., 2018). Several contradicted in vivo/ in vitro reports are available regarding nanomaterials toxicity. Several chemically different engineered nanomaterials like fullerenes, CNT and metal oxides are reported to exhibit enhanced oxidative stress (Bonner, 2007). Foremost causes of formation of reactive oxygen species (ROS) due to NPs exposure include the presence of pro-oxidant functional groups on the surface of NPs, active redox reactions happening on the surface of NPs especially in case of MNPs and various interactions between cells and NPs. Entry of NPs inside the cells can activate various cells of the immune system like macrophages and neutrophils that are potent phagocytes and generate ROS/reactive nitrogen species (RNS) once activated (Ambwani et al., 2015; Datta et al., 2018). Current studies have shown the destruction of target cells through entry of nanoshells and nanotubes inside the animal body (Jain et al., 2010). Toxic effects of NPs are due to various attributes of nanomaterials, their dose and route of exposure. Another important aspect in toxicity profiling of NPs is that inconsistent results are obtained in vitro and in vivo toxicity analysis of same NPs. Presently there are no guidelines or standard procedures in place for methodical toxicological analysis of engineered NPs.The imprecise and inconsistent conclusions related to NPs toxicity shed disbelief on the potential of nanomedicine and cause pointless apprehensions in the public mindset (Yildirimer et al., 2011). However, suitable nano-herbal formulations can be prepared with relevant knowledge and forethought after a thorough analysis of various interactions between engineered NPs and target cells, resultant toxicity, and its molecular basis.

\section{Conclusion and future perspectives}

The treatment of any disease can be improved either by development of better drugs or with more effective and safer use of existing drugs. Various nano-based drug delivery approaches have attracted the attention of the researchers. Approaches for drug delivery have undergone many changes involving advanced materials and new physical or chemical effects. The conventional methods of drug delivery offer limitations in the progress of efficacious herbal drug development because oral or parenteral herbal formulations are not found to be efficient due to several drawbacks involved. Modern therapeutic approaches involving usage of proteins and nucleic acids need alternative delivery systems so as to reduce their toxic effects and increase their curative potential. Thus it could be concluded that usage of NDS could be of paramount importance in designing herbal formulations. Nanocarriers based herbal drug delivery systems have shown immense potential in case of many diseases and disorders especially in the development of cancer therapeutics because of their ability to infiltrate the reticuloendothelial system, increased stability, retention and penetration and specific tissue/ tumor targeting. NPs based herbal formulations have demonstrated increased uptake, bioavailability, and accurate delivery. NDS have shown the ability to stabilize the drug molecules which could get quickly degraded in the physiological conditions with effective drug molecule distribution and insignificant toxicity. Anatomic obstacles such as the BBB, branching channels of the pulmonary system and tight epithelial junctions of the skin, etc., make many desired physiologic targets unreachable. In such instances, the drug-loaded multi-layered nanocarrier assemblies could be of tremendous use which gets degraded inside the biological system layer by layer as it traverses through each barrier and finally delivering the drug at its target site. Salient advantages of NDS include their potential for cellular drug delivery and capacity to target drug molecules to specific tissues/ tumorous cells.

Throughout the world, herbal remedies and natural products are gaining momentum and their scientific rationales have been investigated. Thus merger of "herbal remedy" with nanocarriers would enhance their efficacy for treating different chronic diseases. The development of nanosized herbal remedies is going on in various biomedical research institutions either are at initial or clinical trial levels. The salient features required in case of herbal drugs are their site-directed sustained delivery with enhanced curative potential, patient compliance and without unwanted toxic side effects and hypersensitive reactions, etc. Hence, NDS based herbal formulations will boost their ability to treat different chronic health conditions and impart tremendous fitness benefits. This type of multidisciplinary research including traditional herbal therapeutics together with novel modern drug delivery systems has given way to the development of attractive nanosized herbal drugs as future phytopharmaceuticals that would prove to be of paramount value for enhancing the health of people. 


\section{References}

Aggarwal D, Nautiyal U (2016) Ethosomes: A review. International journal of pharmaceutical and medical research $4: 354-363$.

Aisha AFA, Amin MSAM, Zhari I (2014) Preparation and characterization of nano liposomes of Orthosiphon stamineus ethanolic extract in soybean phospholipids. BMC Biotechnology 14: 23-34.

Ambwani S, Tandon R, Gupta A, Ambwani TK, Chauhan RS (2015) Nanoparticles: Utility, immuno-toxicology and ethical issues. Journal of Immunology and Immunopathology 17: 68-78.

Ambwani S, Kakade DP, Kandpal D, Arora S, Ambwani TK (2016) Cytotoxic effects of gold nanoparticles exposure employing in vitro animal cell culture system as part of nanobiosafety. AIP Conference Proceedings 1724, 020091 (2016); doi: http://dx.doi.org/10.1063/1.4945211.

Ansari SH, Islam F, Sameem M (2012) Influence of nanotechnology on herbal drugs: A Review. Journal of Advanced Pharmaceutical Technology \& Research 3: 142-146.

Aqil F, Munagala R, Jeyabalan J, Vadhanam MV (2013) Bioavailability of phytochemicals and its enhancement by drug delivery systems. Cancer Letters 334 : 133-141.

Arora R, Kuhad A, Kaur IP, Chopra K (2015) Curcumin loaded solid lipid nanoparticles ameliorate adjuvantinduced arthritis in rats. European Journal of Pain 19 : 940- 952

Bagheri L, Madadlou A, Yarmand M, Mousavi ME (2013) Nanoencapsulation of date palm pit extract in whey protein particles generated via desolvation method. Food Research International 51: 866871.

Bakry R, Vallant M, Najam-Ul-Haq M, Rainer M, Szabo Z, Huck CW, Bonn GK (2007) Medicinal Applications of Fullerenes. International Journal of Nanomedicine 2(4): 639-649.

Balakrishnan P, Shanmugam S, Lee WS, Lee WM, Kim JO, Oh DH (2009) Formulation and in vitro assessment of minoxidil niosomes for enhanced skin delivery. International Journal of Pharmaceutics 377:1-8.

Baldissera MD, Da Silva AS, Oliveira CB, Zimmermann CE, Vaucher RA, Santos RC, Rech VC, Tonin AA, Giongo JL, Mattos CB, Koester L, Santurio JM, Monteiro SG (2013) Trypanocidal activity of the essential oils in their conventional and nanoemulsion forms: in vitro tests. Experimental Parasitology 134:356-361. doi 10.1016/j.exppara.2013.03.035.

Belletti D, Riva G, Luppi M, Tosi G, Forni F, Vandelli MA, Ruozi B, Pederzoli F (2017) Anticancer drug-loaded quantum dots engineered polymeric nanoparticles: Diagnosis/therapy combined approach. European Journal of Pharmaceutical Sciences 107: 230-239.

Bhattacharya R, Mukherjee P (2008) Biological properties of "naked" metal nanoparticles. Advanced Drug Delivery Reviews 60: 1289-1306.

Bhattacharya S (2009) Phytosomes: Emerging strategy in delivery of herbal drugs and nutraceuticals. Pharma Times 41: 9-12.

Bhokare SG, Dongaonkar CC, Lahane SV, Salunke PB, Sawale VS, Thombare MS (2016) Herbal novel drug delivery- a review. World Journal of Pharmacy and Pharmaceutical Sciences 5 : 593-611.

Bilia AR, Guccione C, Isacchi B, Righeschi C, Firenzuoli F, Bergonzi MC (2014a) Essential oils loaded in nanosystems: A developing strategy for a successful therapeutic approach. Evidence-Based Complementary and Alternative Medicine 2014:651593. doi: 10.1155/2014/651593.

Bilia AR, Isacchi B, Righeschi C, Guccione C, Bergonzi MC (2014b) Flavonoids Loaded in Nanocarriers: An Opportunity to Increase Oral Bioavailability and Bioefficacy. Food and Nutrition Sciences 5: 1212-1227.
Bisht S, Feldmann G, Soni S, Ravi R, Karikar C, Maitra A, Maitra A (2007) Polymeric nanoparticle-encapsulated curcumin ("nanocurcumin"): A novel strategy for human cancer therapy. Journal of Nanobiotechnology 5: 3 DOI:10.1186/1477-3155-5-3.

Bonifácio BV, Silva PB, Ramos MA, Negri KM, Bauab TM, Chorilli M (2014) Nanotechnology-based drug delivery systems and herbal medicines: A review. International Journal of Nanomedicine 1-15.

Bonner JC (2007) Lung fibrotic responses to particle exposure. Toxicologic Pathology 35: 148-153.

Campos DA, Madureira AR, Sarmento B, Gomes AM, Pintado MM (2015) Stability of bioactive solid lipid nanoparticles loaded with herbal extracts when exposed to simulated gastrointestinal tract conditions. Food Research International 78: 131-140.

Cargnelutti LO, Denardi L, Boligon A (2016) A new biodegradable polymeric nanoparticle formulation containing Syzygiumcumini: Phytochemical profile, antioxidant and antifungal activity and in vivo toxicity. Industrial Crops and Products 83: 400-407.

Celia C, Cilurzo F, Trapasso F, Cosco D, Fresta M, Paolino D (2012) Ethosomes ${ }^{\circledR}$ and transfersomes containing linoleic acid: Physicochemical and technological features of topical drug delivery carriers for the potential treatment of melasma disorders. Biomedical Microdevices 14:119-130.

Cha C, Shin SR, Annabi N, Dokmeci MR, Khademhosseini A (2013) Carbon-based nanomaterials: Multi-functional Materials for Biomedical Engineering. ACS Nano 7:2891-2897.

Chan ES, Yim ZH, Phan SH, Mansa RF, Ravindra P (2010) Encapsulation of herbal aqueous extract through absorption with ca-alginate hydrogel beads. Food and Bioproducts Processing 88: 195-201.

Chandu V P, Arunachalam A, Jeganath S, Yamini K, Tharangini K, Chaitanya G (2012) Niosomes: A Novel Drug Delivery System. International Journal of Novel Trends in Pharmaceutical Sciences 2: 25-31.

Chao P, Deshmukh M, Kutscher HL, Gao D, Rajan SS, Hu P, Laskin DL, Stein S, Sinko PJ (2010) Pulmonary targeting microparticulate camptothecin delivery system: Anti-cancer evaluation in a rat orthotopic lung cancer model. Anti-Cancer Drugs 21: 10.1097/CAD.0b013e328332a322.

Charman WN, Chan HK, Finnin BC, Charman SA (1999) Drug delivery: A key factor in realising the full therapeutic potential of drugs. Drug Development Research 46:316-27

Chaudhary H, Kohli K, Kumar V (2014) A novel nano-carrier transdermal gel against inflammation. International Journal of Pharmaceutics 465: $175-186$

Chen CYC, Wu CH (2008) Magnolol encapsulated by liposome in inhibiting smooth muscle cell proliferation. Journal of the Chinese Chemical Society 55: 517- 521

Chen H, Chang X, Du D, Liu W, Liu J, Weng T, Yang Y, Xu H, Yang X (2006) Podophyllotoxin-loaded solid lipid nanoparticles for epidermal targeting. Journal of Controlled Release 110: 296-306.

Chen J-G, Jiang Y, Yang Zb (2012) Preparation of triptolide ethosomes. African Journal of Pharmacy and Pharmacology 6: 1341-1347.

Chen JG, Wei L, Yu J (2013) Preparation of curcumin ethosomes. African Journal of Pharmacy and Pharmacology 7: 2246-2251.

Chen Y, Lin X, Park H, Greever R (2009) Study of artemisinin nanocapsules as anticancer drug delivery systems. Nanomedicine: Nanotechnology, Biology and Medicine 5: 316-322.

Conacher M, Alexander J, Brewer JM (2000) Niosomes as immunological adjuvants. In Uchegbu IF (Ed.) "Synthetic Surfactant Vesicles" International Publishers Distributors Ltd. Singapore, Pp. 185-205.

Conte R, Marturano V, Peluso G, Calarco A, Cerruti P (2017) Recent Advances in Nanoparticle-Mediated Delivery of Anti-Inflammatory 
Phytocompounds. International Journal of Molecular Sciences 18: 709; doi: 10.3390/ijms18040709.

Costa DFG, Franca JR, Ribeiro TG, Kaplan MAC, Faraco AAG, Castilho RO (2013) Development and characterization of polymeric nanoparticles as Barbatimão (Stryphnodendron obovatum) standardized fraction carrier. Advances in Bioscience and Biotechnology 4: 89-92. DOI: http://dx.doi.org/10.4236/abb.2013.41013.

Crielaard BJ, Wal VD, Le HT, Bode AT, Lammers T, Hennink WE, Schiffelers RM, Fens MH, Storm G (2012) Liposomes as carriers for colchicines derived produrgs: vascular disrupting nanomedicnes with tailorable drug release kinetics. European Journal of Pharmaceutical Sciences 45: 429-435.

Datta PK, Arora S, Ambwani S (2018) Cytotoxic effect of silver nanoparticles in cancerous $\mathrm{HeLa}$ cells due to enhanced oxidative stress. Research Journal of Biotechnology 13: 68-74.

Dave V, Pareek A, Paliwal S (2012) Ethosome: A novel approach of transdermal drug delivery system. International Journal of Pharma and Bio Sciences 1:439-452.

Dayan N, Touitou E (2000) Carriers for skin delivery of trihexyphenidyl $\mathrm{HCl}$ : Ethosomes vs liposomes. Biomaterials 21: 1879-1885.

Dhule SS, Penfornis P, Frazier T, Walker R, Feldman J, Tan G, He J, Alb A, John V, Pochampally R (2012) Curcumin-loaded $\gamma$-cyclodextrin liposomal nanoparticles as delivery vehicles for osteosarcoma. Nanomedicine: Nanotechnology, Biology and Medicine 8: 440-451.

Dilnawaz F, Singh A, Mohanty C, Sahoo SK (2010) Dual drug loaded superparamagnetic iron oxide nanoparticles for targeted cancer therapy. Biomaterials 31: 3694-3706

Dornian D, Hussein MZ, Kura AU, Fakurazi S, Shaari AH, Ahmad Z (2012) Preparation of $\mathrm{Fe}_{3} \mathrm{O}_{4}$ magnetic nanoparticles coated with gallic acid for drug delivery. International Journal of Nanomedicine 7: 5745-756.

Dua JS, Rana AC, Bhandari AK (2012) Liposomes: Method of preparation and application. International Journal of Pharmaceutical Sciences and Research 3:14-20.

Dube A, Nicolazzo JA, Larson I (2010) Chitosan Nanoparticles Enhance the Intestinal Absorption of the Green Tea Catechins (+)-Catechin and (-) Epigallocatechin Gallate. European Journal of Pharmaceutical Sciences 41: 219- 225 .

Dwivedi P, Khatik R, Khandelwal K, Taneja I, Raju KSR, Paliwal SK, Dwivedi AK, Mishra PR (2014) Pharmacokinetics study of arteether loaded solid lipid nanoparticles: An improved oral bioavailability in rats. International Journal of Pharmaceutics 466: 321-327.

Ebrahimnezhad Z, Zarghami N, Keyhani M, Amirsaadat S, Akbarzadeh A Rahmati M, Taheri MZ, Nejati-Koshki K (2013) Inhibition of hTERT Gene Expression by Silibinin-Loaded PLGA-PEG-Fe3O4 in T47D Breast Cancer Cell Line. Bioimpacts 3: 67-74

Edmundson M C, Capeness M, Horsfall L (2014) Exploring the potential of metallic nanoparticles within synthetic biology. New Biotechnology 31 : 572-578.

Ekambaram P, Sathali AAH, Priyanka K (2012) Solid Lipid Nanoparticles: A Review. Scientific Reviews \& Chemical Communications 2: 80-102.

Ekor M (2013) The growing use of herbal medicines: issues relating to adverse reactions and challenges in monitoring safety. Frontiers in Pharmacology 4: 177-186.

Elmowafy M, Viitala T, Ibrahim HM, Abu-Elyazid SK, Samy A, Kassem A (2013) Silymarin loaded liposomes for hepatic targeting: In vitro evaluation and HepG2 drug uptake. European Journal of Pharmaceutical Sciences 50:161-171.
Esmaeili A, Niknam S (2013) Characterization of nanocapsules containing Elaeagnus angustifolia L. extract prepared using an emulsiondiffusion process. Flavour and Fragrance Journal 28: 309-315.

Esmaeili A, Ebrahimzadeh M (2015) Preparation of Polyamide Nanocapsules of Aloe vera L. Delivery with In Vivo Studies. American Association of Pharmaceutical Scientists 16: 242-249.

Fatima GX, Rahul Raj S, Reshma I, Sandeep T, Shanmuganathan S, Chamundeeswari D (2014) Herbal Ethosomes - A Novel Approach in Herbal Drug Technology. American Journal of Ethnomedicine 1: 226-230.

Gadkari PV, Balaraman M (2015) Extraction of catechins from decaffeinated green tea for development of nanoemulsion using palm oil and sunflower oil based lipid carrier systems. Journal of Food Engineering 147: $14-23$

Galib, Barve M, Mashru M, Jagtap C, Patgiri BJ, Prajapati PK (2011) Therapeutic potentials of metals in ancient India: A review through Charaka Samhita. Journal of Ayurveda and Integrative Medicine 2 : 55-63.

Gandhi A, Dutta A, Pal A, Bakshi P (2012) Recent trends of phytosomes for delivering herbal extract with improved bioavailability. Journal of Pharmacognosy and Phytochemistry 1: 6-14.

Ganesan P, Arulselvan P, Choi DK (2017) Phytobioactivecompound-based nanodelivery systems for the treatment of type 2 diabetes mellitus - current status. International Journal of Nanomedicine 12: 1097-1111.

Geetha R, Ashokkumar T, Tamilselvan S, Govindaraju K, Sadiq M (2013) Green synthesis of gold nanoparticles and their anticancer activity. Cancer Nanotechnology 4: 91-98.

Gibis M, Zeeb B, Weiss J (2014) Formation, characterization, and stability of encapsulated hibiscus extract in multilayered liposomes. Food Hydrocolloids 38: 28-39.

Gomes A, Ghosh S, Sengupta J, Datta P, Gomes A (2014) Herbonanoceuticals: A New Step towards Herbal Therapeutics. Medicinal and Aromatic Plants 3: 162. doi:10.4172/2167-0412.1000162.

González-Rodríguez ML, Rabasco AM (2011) Charged liposomes as carriers to enhance the permeation through the skin. Expert Opinion on Drug Delivery $8: 857-871$

Govindarajan Karthivashan, Palanivel Ganesan, Shin-Young Park, JoonSoo Kim, Dong-Kug Choi (2018) Therapeutic strategies and nano-drug delivery applications in management of ageing Alzheimer's disease. Drug Delivery, 25:1, 307-320, DOI: 10.1080/10717544.2018.1428243.

Goyal A, Kumar S, Nagpal M, Singh I, Arora S (2011) Potential of novel drug delivery systems for herbal drugs. Indian Journal of Pharmaceutical Education and Research 45: 225-35.

Greenwell M, Rahman PKSM (2015) Medicinal Plants: Their Use in Anticancer Treatment. International Journal of Pharmaceutical Sciences and Research $6: 4103-4112$.

Griggs B (1982) Green Pharmacy: A History of Herbal Medicine. Viking Press, New York.

Gunasekaran T, Haile T, Nigusse T, Dhanaraju MD (2014). Nanotechnology: an effective tool for enhancing bioavailability and bioactivity of phytomedicine. Asian Pacific Journal of Tropical Biomedicine 4 : S1-S7.

Guterres SS, Alves MP, Pohlmann AR (2007) Polymeric Nanoparticles, Nanospheres and Nanocapsules for Cutaneous Applications. Drug Target Insights 2: 147-157

He X, Li Q, Liu X, Wu G, Zhai G (2015) Curcumin-Loaded Lipid Cubic Liquid Crystalline Nanoparticles: Preparation, Optimization, Physicochemical Properties and Oral Absorption. Journal of Nanoscience and Nanotechnology 15: 5559-5565. 
Hosseini SF, Zandi M, Rezaei M, Farahmandghavi F (2013) Two-step method for encapsulation of oregano essential oil in chitosan nanoparticles: Preparation, characterization and in vitro release study. Carbohydrate polymers 95: 50-56.

Hourani R, Kakkar A (2010) Advances in the elegance of chemistry in designing dendrimers. Macromolecular rapid communications 31: 947974.

Husch J, Bohnet J, Fricker G, Skarke C, Artaria C, Appendino G, Schubert-Zsilavecz M, Abdel-Tawab M (2013) Enhanced absorption of boswellic acids by a lecithin delivery form (phytosome ${ }^{\circledR}$ ) of boswellia extract. Fitoterapia 84: 89-98.

Iram F, Iqbal MS, Athar MM, Saeed MZ, Yasmeen A (2014) Glucoxylanmediated green synthesis of gold and silver nanoparticles and their phytotoxicity study. Carbohydrate Polymers 104: 29-33.

Iravani S (2011) Green synthesis of metal nanoparticles using plants. Green Chemistry 13: 2638-2650

Jadhav N, Powar T, Shinde S, Nadaf S (2014) Herbal nanoparticles: A patent review. Asian journal of Pharmaceutics 8 : 1-12.

Jain K, Kesharwani P, Gupta U, Jain N (2010) Dendrimer toxicity: Let's meet the challenge. International Journal of Pharmaceutics 394: 122-142.

Jantarat C (2013) Bioavailability Enhancement Techniques of Herbal Medicine: A Case Example of Curcumin. International Journal of Pharmacy and Pharmaceutical Sciences 5: 493-500.

Jia D, Barwal I, Thakur S, Yadav SC (2015) Methodology to nanoencapsulate hepatoprotective components from Picrorhiza kurroa as food supplement. Food Bioscience 9: 28-35.

Jiang HL, Cui YL, Qi Y (2013) Microencapsulation of rutin in chitosancoated alginate microspheres through internal gelation technique. Advanced Materials Research 716: 433-458.

Jourghanian P, Ghaffari S, Ardjmand M, Haghighat S, Mohammadnejad M (2016) Sustained release Curcumin loaded Solid Lipid Nanoparticles. Advanced Pharmaceutical Bulletin $6: 17-21$.

Juzenas P, Chen W, Sun YP, Coelho MAN, Generalov R, Generalova N, Christensen IL (2008) Quantum dots and nanoparticles for photodynamic and radiation therapies of cancer. Advanced Drug Delivery Reviews 60: 1600-1614.

Kalele S, Gosavi S W, Urban J, Kulkarni S K (2006) Nanoshell particles: synthesis, properties and applications. Current Science 91:1038-1105.

Kalita B, Das MK, Sharma AK (2013) Novel phytosome formulations in making herbal extracts more effective. Research Journal of Pharmacy and Technology 6: 1295-1301.

Kaminskas LM, Boyd BJ, Porter CJ (2011) Dendrimer pharmacokinetics: The effect of size, structure and surface characteristics on ADME properties. Nanomedicine 6: 1063-1084.

Kannan S, Dai H, Navath RS, Balakrishnan B, Jyoti A, Janisse J, Romero R, Kannan RM (2012) Dendrimer-based postnatal therapy for neuroinflammation and cerebral palsy in a rabbit model. Science Translational Medicine 4: 130-146.

Kareparamban JA, Nikam PH, Jadhav AP, Kadam VJ (2012) Phytosome: A novel revolution in herbal drugs. International Journal of Research in Pharmacy and Chemistry 2: 299-310.

Karimi N, Ghanbarzadeh M, Hamishehkar H, Pezeshki A, Mostafayi H , Gholian MM (2015) Phytosome as novel delivery system for nutraceutical materials. International Journal of Current Microbiology and Applied Sciences 4: 152-159.

Kesarwani K, Gupta R (2013) Bioavailability enhancers of herbal origin: An overview. Asian Pacific Journal Of Tropical Biomedicine 3: 253-266.

Khan A, Shukla Y, Kalra N, Alam M, Ahmad MG, Hakim SR, Owais M (2007) Potential of diallyl sulfide bearing $\mathrm{pH}$-sensitive liposomes in chemoprevention against DMBA-induced skin papilloma. Molecular Medicine 13: 443-451.

Kingston DGI (2011) Modern natural products drug discovery and its relevance to biodiversity conservation. Journal of Natural Products 74:496-511.

Krausz AE, Adler BL, Cabral V, Navati M, Doerner J, Charafeddine RA (2015) Curcumin-encapsulated nanoparticles as innovative antimicrobial and wound healing agent. Nanomedicine 11:195-206 doi: 10.1016/j.nano.2014.09.004.

Krug HF, Wick P (2011) Nanotoxicology: an interdisciplinary challenge. Angewandte Chemie International Edition 50: 1260-1278.

Kumar AB, Habbu P, Thimmasetty L, Hullatti P, Kumar RS (2017) Phytosomes as Novel Drug Delivery System for Herbal Medicine Systematic Reviews in Pharmacy 8: 5-7.

Kumar K, Rai AK (2012) Evaluation of ant-inflammatory and anti-arthritic activities of floating microsphere of herbal drug. International Research Journal of Pharmacy $3: 186-193$.

Kumar KP, Radhika P, Sivakumar T (2010) Ethosomes-a priority in transdermal drug delivery. International Journal of Advances in Pharmaceutical Sciences 1: 111-121.

Kumar P, Kulkarni PK, Srivastava AA (2015) Pharmaceutical application of nanoparticles in drug delivery system. Journal of Chemical and Pharmaceutical Research 7: 703-712.

Kumbhani J, Tank C, Upadhyay J, Darshit R, Nirali T, Hetal S (2016) Nanoparticle: A Promising carrier for Novel Drug Delivery. International Journal of Pharma Research \& Review 5 : 27-40.

Kwon MC, Choi WY, Seo YC, Kim JS, Yoon CS, Lim HW, Kim HS, Hee Ahn J, Lee HY (2012) Enhancement of the skin-protective activities of centella asiatica 1. Urban by a nano-encapsulation process. Journal of Biotechnology 157: 100-106.

Lai Wing-Fu, Rogach AL (2017) Hydrogel-Based Materials for Delivery of Herbal Medicines ACS Applied Materials \& Interfaces 9: 1130911320 .

Landfester K, Musyanovych A, Mailänder V (2010) From polymeric particles to multifunctional nanocapsules for biomedical applications using the miniemulsion process. Journal of Polymer Science Part A: Polymer Chemistry 48: 493-515.

Laouini A, Maalej CJ, Blouza IL, Sfar S, Charcosset C, Fessi H (2012) Preparation, characterization and applications of liposomes: State of the art. Journal of Colloid Science and Biotechnology 1:147-68.

Lee DR, Park JS, Bae IH , Lee Y, Kim BM (2016) Liquid crystal nanoparticle formulation as an oral drug delivery system for liver-specific distribution. International Journal of Nanomedicine 11: 853-871.

Lei W, Yu C, Lin H (2013) Development of tacrolimus-loaded transfersomes for deeper skin penetration enhancement and therapeutic effect improvement in vivo. Asian Journal of Pharmaceutical Sciences 8:336-345

Lertsutthiwong $\mathrm{P}$, Noomun $\mathrm{K}$, Jongaroonngamsang $\mathrm{N}$, Rojsitthisak P, Nimmannit U (2008) Preparation of alginate nanocapsules containing turmeric oil. Carbohydrate polymers 74: 209-214.

Lin A, Li H, Liu Y, QIU X (2007) Preparation and release characteristics of berberine chitosan nanoparticles in vitro. China Pharmacy 18: 755-757.

Liu M, Dong J, Yang Y, Yang X, Xu H (2005) Anti-inflammatory effects of triptolide loaded poly (d.l-lactic acid) nanoparticles on an adjuvantinduced arthritis in rats. Journal of Ethnopharmacology, 97: 219-225.

Lohumi A, Rawat S, Sarkar S (2012) A novel drug delivery system: Niosomes review. Journal of Drug Delivery and Therapeutics 2:129-135.

Long X, Luo J, Li L, Lin D, Rong H, Huang W (2006). Preparation and in vitro evaluations of topically applied capsaicin transfersomes. China journal of Chinese material medica 31: 981-984. 
Lu Y, Hou S, Chen T, Sun Y, Yang B, Yuan Z (2005) Preparation of transfersomes of vincristine sulfate and study on its prcutaneous penetration. China journal of Chinese Materia Medica 30: 900-903.

Madaan K, Lather V, Pandita D (2016) Evaluation of polyamidoamine dendrimers as potential carriers for quercetin, a versatile flavonoid. Drug Delivery 23 : 254-262.

Maestrelli F, Capasso G, González-Rodríguez ML, Rabasco AM, Ghelardini C, Mura P (2009) Effect of preparation technique on the properties and in vivo efficacy of benzocaine-loaded ethosomes. Journal of Liposome Research 19: 253-260.

Mahajan A, Mangat P, Bhatia A, Katare O (2010) A novel herbal capsaicin loaded liposomal formulation: Design, development and evaluation. Pharmaceutical sciences 1-10

Mahima, Rahal A, Deb R, Latheef SK, Samad HA, Tiwari R, Verma AK, Kumar A, Dhama K (2012) Immunomodulatory and therapeutic potentials of herbal, traditional/indigenous and ethnoveterinary medicines. Pakistan Journal of Biological Sciences 15: 754-774.

Maiti K, Mukherjee K, Gantait A, Saha BP, Mukherjee PK (2007) Curcumin-phospholipid complex: Preparation, therapeutic evaluation and pharmacokinetic study in rats. International Journal of Pharmaceutics 330: $155-163$

Makarov VV, Love AJ, Sinitsyna OV, Makarova SS, Yaminsky IV, Taliansky ME, Kalinina NO (2014) Green nanotechnologies: Synthesis of metal nanoparticles using plants. Acta Naturae 6: 35-44.

Makeshwar KB, Wasankar SR (2013) Niosome: a Novel Drug Delivery System. Asian Journal of Pharmaceutical Research 3 : 16-20.

Mamillapalli V, Atmakuri AM, Khantamneni P (2016) Nanoparticles for herbal extracts. Asian Journal of Pharmaceutics 10 : S54-S60.

Man DKM, Casettari L, Cespi M, Bonacucina G, Palmieri GF, Sze SCW, Leung GPH, Lam JKW and Kwok PCL (2015) Oleanolic acid-loaded PEGylated PLA and PLGA nanoparticles with enhanced cytotoxic activity against cancer cells. Molecular Pharmaceutics 12: 2112-2125.

Manach C, Williamson G, Morand C, Scalbert A, Rémésy C (2005). Bioavailability and Bioefficacy of Polyphenols in Humans. I. Review of 97 Bioavailability Studies American Journal of Clinical Nutrition 81: 230-242.

Manjili H, Malvandi H, Mousavi MS, Danafar H (2016) Preparation and physicochemical characterization of biodegradable mpeg-pcl coreshell micelles for delivery of artemisinin. Journal of Pharmaceutical Sciences 22: $234-243$.

Mathur M (2016) Achievements, constraints and gaps of nano-techniques pertains to augmenting herbal drug efficacy. Medicinal Plants 8 : 171-198.

McBain SC, Yiu HH, Dobson J (2008) Magnetic nanoparticles for gene and drug delivery. International Journal of Nanomedicine 3: 169-180.

Mei Z, Chen H, Weng T, Yang Y, Yang X (2003) Solid lipid nanoparticle and microemulsion for topical delivery of triptolide. European Journal of Pharmaceutics and Biopharmaceutics 56:189-196. DOI10.1016/S09396411(03)00067-5

Mei Z, Li X, Wu Q, Hu S, Yang X (2005) The research on the antiinflammatory activity and hepatotoxicity of triptolide-loaded solid lipid nanoparticle. Pharmacological Research 51:345-351.

Min KH, Park K, Kim YS, Bae SM, Lee S, Jo HG, Park RW, Kim IS, Jeong SY, Kim K, Kwon IC (2008) Hydrophobically modified glycol chitosan nanoparticles-encapsulated camptothecin enhance the drug stability and tumor targeting in cancer therapy. Journal of Controlled Release 127: 208-218

Moghassemi S, Hadjizadeh A (2014) Nano-niosomes as nanoscale drug delivery systems: An illustrated review. Journal of Controlled Release 185: $22-36$
More SB, Nandgude DT, Poddar SS (2016) Vesicles as a Tool for Enhanced Topical Drug Delivery. Asian Journal of Pharmaceutics 10 : S196.

Mukherjee S, Ray S, Thakur RS (2009) Solid Lipid Nanoparticles: A Modern Formulation Approach in Drug Delivery System. Indian Journal of Pharmacy 71: 349-358.

Mukundan D, Mohankumar R, Vasanthakumari R (2015) Green synthesis of silver nanoparticles using leaves extract of Bauhinia tomentosa Linn and its in vitro anticancer potential. Materials Today: Proceedings 29 Part A: 4309-4316.

Mulder WJ, Strijkers GJ, Van Tilborg GA, Cormode DP, Fayad ZA, Nicolay K (2009) Nanoparticulate assemblies of amphiphiles and diagnostically active materials for multimodality imaging. Accounts of Chemical Research 42: 904-914.

Nagalakshmi SK, Kalaiaperumal JM, Arul, Chaudhari PS, Pushpalatha HB, Shanmuganthan S (2016) Fabrication and Characterization of Herbal Drug -Loaded Nonionic Surfactant Based Niosomal Topical Gel. Journal of Pharmaceutical Sciences and Research 8 : 1271-1278

Nagavarma BVN, Yadav HKS, Ayaz A, Vasudha LS, Shivakumar HG (2012) Different techniques for preparation of polymeric nanoparticles- a review. Asian Journal of Pharmaceutical and Clinical Research 5(3): $16-23$

Naghsh F (2015) Nano Drug Delivery Study of Anticancer Properties on Ginger using QM/MM Methods. Oriental Journal of Chemistry 31: 465-

Nirved U, Lokesh V, Prasad MG, Joshi HM (2012) Formulation and evaluation of ethosomes of Sesbania grandiflora linn. Seeds Novel Sciences. International Journal of Pharmacy and Pharmaceutical Sciences 1: 274-275.

Pal D, Sahu CK, Haldar A (2014) Bhasma: The ancient Indian nanomedicine. Journal of Advanced Pharmaceutical Technology \& Research 5: 4-12.

Paolino D, Lucania G, Mardente D, Alhaique F, Fresta M (2005) Ethosomes for skin delivery of ammonium glycyrrhizinate: In vitro percutaneous permeation through human skin and in vivo antiinflammatory activity on human volunteers. Journal of Controlled Release 106: $99-110$

Papagiannaros A, Upponi J, Hartner W, Mongayt D, Levchenko T, Torchilin V (2010) Quantum dot loaded immunomicelles for tumor imaging. BMC Medical Imaging 10: 22.

Park K (2014) Controlled drug delivery systems: Past forward and future back. Journal of Control Release 190: 3-8.

Patel A, Tanwar Y, Rakesh S, Patel P (2013) Phytosome: Phytolipid Drug Delivery System for Improving Bioavailability of Herbal Drug. Journal of Pharmaceutical Science and Bio scientific Research 3: 51-57.

Patel HN, Patel DRPM (2013) Dendrimer applications-A review. International Journal of Pharma and Bio Sciences 9: 454-463.

Patel R, Singh SK, Singh S, Sheth NR, Gendle R (2009) Development and characterization of curcumin loaded transferosomes for trasnsdermal delivery. Journal of Pharmaceutical Sciences 1: 71-80.

Patwardhan B, Vaidya AD, Chorghade M (2004) Ayurveda and natural products drug discovery. Current Science 86: 789-799.

Paul S, Chugh A (2011) Assessing the role of Ayurvedic 'Bhasmas' as Ethno-nanomedicine in the metal based nanomedicine patent regime. Journal of Intellectual Disability Research 16: 509-515.

Pavani T, Chakra Ch S, Rao KV (2013) A green approach for the synthesis of nano-sized iron oxide, by Indian Ayurvedic modified bhasmikaran method. American Journal of Pharmaceutical Sciences 1: 1-7. 
Pawar HA, Bhangale BD (2015) Phytosome as a Novel Biomedicine: A Microencapsulated Drug Delivery System. Journal of Bioanalysis \& Biomedicine 7: 6-12.

Pawar P, Kalamkar R, Jain A, Amberkar S (2015) Ethosomes: A Novel Tool for Herbal Drug Delivery. International journal of pharmacy and Pharmaceutical Research 3: 191-202.

Priprem A, Janpim K, Nualkaew S, Mahakunakorn P (2016) Topical Niosome Gel of Zingiber cassumunar Roxb. Extract for Antiinflammatory Activity Enhanced Skin Permeation and Stability of Compound D. AAPS PharmSciTech 17: 631-639.

Priprem A, Sutthiparinyanont S, Young JS, Chulasiri M (2015) Effect of formulations of nanosized quercetin liposomes on COX-2 and NF-kB in MCF-10A cells. Pharmaceutical Nanotechnology 1:26-34.

Rahman L, Arisanty, Manggau MA (2015b). Niosomal transdermal gel formulation of curcumin having anti-inflammatory effect in experimental rat models. Journal of Chemical and Pharmaceutical Research 7: 843-849

Rahman L, Ningsi S, Muslimin L, Manggau AM (2015a) Formulation and Characterization of Bioadhesive Vaginal Cream of Nanocapsule of Parang Romang (Boehmeria virgata (Forst) Guill) Leaf Extract. International Journal of Pharmaceutical Sciences Review and Research 30 : 149-152.

Ramos MADS, Calixto G, Toledo LGD, Bonifacio BV, Santos LCD, Almeida MTGD, Chorilli M, Bauab TM (2015) Liquid Crystal Precursor Mucoadhesive System as a Strategy to Improve the Prophylactic Action of Syngonanthus Nitens (Bong.) Ruhland against Infection by Candida Krusei. International Journal of Nanomedicine 10: 7455-7466.

Rao PV, Nallappan D, Madhavi K, Rahman S, Wei LJ, Gan S (2016) Phytochemicals and Biogenic Metallic Nanoparticles as Anticancer Agents. Oxidative Medicine and Cellular Longevity 2016: Article ID 3685671, 15 pages http://dx.doi.org/10.1155/2016/3685671

Sachan AK, Gupta A (2015) A review on nanotized herbal drugs. International Journal of Pharmaceutical Sciences and Research 6: 961-970.

Sadat SMA, Jahan ST, Haddadi A (2016) Effects of Size and Surface Charge of Polymeric Nanoparticles on in vitro and in vivo Applications. Journal of Biomaterials and Nanobiotechnology 7: 91-108.

Sahu A, Bora U, Kasoju N, Goswami P (2008) Synthesis of novel biodegradable and selfassembling methoxy poly (ethylene glycol)palmitate nanocarrier for curcumin delivery to cancer cells. Acta Biomaterialia 4: 1752-1761.

Salmazi R, Calixto G, Bernegossi J, Aparecido dos Santos Ramos M, Bauab TM, Chorilli M (2015) A curcumin-loaded liquid crystal precursor mucoadhesive system for the treatment of vaginal candidiasis. International Journal of Nanomedicine 10: 4815-4824.

Sanna V, Lubinu G, Madau P, Pala N, Nurra S, Mariani A, Sechi M (2015) Polymeric nanoparticles encapsulating white tea extract for nutraceutical application. Journal of Agricultural and Food Chemistry 63: 2026-2032.

Seleci DA, Seleci M, Walter JG, Stahl F, Scheper T (2016) Niosomes as nanoparticular drug carriers: Fundamentals and recent applications. Journal of Nanomaterials, ID 7372306. http://dx.doi.org/10.1155/2016/7372306.

Shah M, Fawcett D, Sharma S, Tripathy SK, Poinern GEJ (2015) Green Synthesis of Metallic Nanoparticles via Biological Entities. Materials 8: 7278-7308.

Sharma A, Mitkare S, Moon R (2011) Multicomponent herbal therapy: A review. International Journal of Pharmaceutical Sciences Review and Research 6: 185-187.

Sharma C, Singh C (2014) Nano Carriers of Novel Drug Delivery System for "Ayurveda Herbal Remedies" Need of Hour- A Bird's Eye View. American Journal of PharmTech Research 4: 60-69.

Sharma P, Verma S, Misri P (2016) Global Need for Novel Herbal Drug Formulations. International Journal of Pharmacognosy and Phytochemical Research 8: 1535-1544.
Shi F, Zhao JH, Liu Y, Wang Z, Zhang YT, Feng NP (2012) Preparation and characterization of solid lipid nanoparticles loaded with frankincense and myrrh oil. International Journal of Nanomedicine 7: 2033-2043.

Singh AK, Prakash P, Singh R, Nandy N, Firdaus Z, Bansal M, Singh RK, Srivastava A, Roy JK, Mishra B, Singh RK (2017) Curcumin Quantum Dots Mediated Degradation of Bacterial Biofilms. Frontiers in Microbiology 8:1517 doi: 10.3389/fmicb.2017.01517.

Singh HP, Utreja P, Tiwary AK, Jain S (2009) Elastic liposomal formulation for sustained delivery of colchicine: in vitro characterization and in vivo evaluation of anti-gout activity. American Association of Pharmaceutical Scientists Journal 11: 54-64.

Singhana B, Slattery P, Chen A, Wallace M, Melancon MP (2014) Lightactivatable gold nanoshells for drug delivery applications. AAPS PharmSciTech 15: 741-752.

Sipai AB, Yadav V, Mamatha Y, Prasanth VV (2012) Liposomes: An overview. Journal of Pharmaceutical and Scientific Innovation 1:13-21.

Spigno G, Donsì F, Amendola D, Sessa M, Ferrari G, De Faveri DM (2013) Nanoencapsulation systems to improve solubility and antioxidant efficiency of a grape marc extract into hazelnut paste. Journal of Food Engineering 114: 207-214.

Spillmann CM, Naciri J, Algar WR, Medintz IL, Delehanty JB (2014) Multifunctional Liquid Crystal Nanoparticles for Intracellular Fluorescent Imaging and Drug Delivery. ACS Nano 8: 6986-6997.

Sravanthi M, Krishna JS (2013) Phytosomes: A Novel Drug Delivery for Herbal Extracts. International Journal of Pharmaceutical Sciences and Research 4: 949-959.

Sugumar S, Clarke S, Nirmala M, Tyagi B, Mukherjee A, Chandrasekaran N (2014) Nanoemulsion of eucalyptus oil and its larvicidal activity against culexquinquefasciatus. Bulletin of Entomological Research 104: 393-402.

Sutthanut K, Lu X, Jay M, Sripanidkulchai B (2009) Solid lipid nanoparticles for topical administration of Kaempferiaparviflora extracts. Journal of Biomedical Nanotechnology $5: 224-232$.

Tan BJ, Liu Y, Chang KL, Lim BK, Chiu GN (2012) Perorally Active Nanomicellar Formulation of Quercetin in the Treatment of Lung Cancer. International Journal of Nanomedicine 7: 651-661.

Tan WB, Zhang Y (2005) Surface modification of gold and quantum dot nanoparticles with chitosan for bioapplications. Journal of Biomedical Materials Research Part A 75: 56-62.

Thillaivanan S, Samraj K (2014) Challenges, Constraints and Opportunities in Herbal Medicines - A Review. International Journal of Herbal Medicine $2: 21-24$

Tongcher O, Sigel R, Landfester K (2006) Liquid Crystal Nanoparticles Prepared as Miniemulsions. Langmuir 22 : 4504-4511.

Tripathi AC, Saraf SA, Saraf SK (2015) Carbon Nanotropes: A Contemporary Paradigm in Drug Delivery. Materials 8: 3068-3100.

Tsoi KM, Dai Q, Alman BA, Chan WCW (2012) Are quantum dots toxic? Exploring the discrepancy between cell culture and animal studies. Accounts of Chemical Research 46: 662-671.

Un RN, Barlas FB, Yavuz M, Seleci DA, Seleci M, Gumus ZP, Demir EGB, Can M, Coskunol H, Timur S (2015) Phyto-Niosomes: In Vitro Assessment of the Novel Nanovesicles Containing Marigold Extract. International Journal of Polymeric Materials and Polymeric Biomaterials 64 : 927-937.

Venkatesh DN, Kalyani K, Tulasi K, Priyanka VS, Abid Ali SK , Kiran HC (2014)Transfersomes: A Novel Technique for Transdermal Drug Delivery. International Journal of Research in Pharmaceutical and Nano Sciences 3: $266-276$

Vicentini FTMC, Casagrande R, VerriJr WA, Georgetti SR, Bentley MVLB, Fonseca MJV(2008) Quercetin in Lyotropic Liquid Crystalline 
Formulations: Physical, Chemical and Functional Stability, AAPS PharmSciTech 9: 591-596.

Vijayakumar KS, Parthiban S, Senthilkumar GP, Mani TT (2014) Ethosomes - A new trends in vesicular approaches for topical drug delivery. Asian Journal of Research in Pharmaceutical Sciences and Biotechnology 2:23-30.

Voigt N, Henrich-Noack P, Kockentiedt S, Hintz W, Tomas J, Sabel BA (2014) Toxicity of polymeric nanoparticles in vivo and in vitro. Journal of Nanoparticle Research 16: 2379.

Wagner E (2007) Programmed drug delivery: Nanosystems for tumor targeting. Expert Opinion on Biological Therapy 7: 587-593.

Wahajuddin, Arora S (2012) Superparamagnetic iron oxide nanoparticles: magnetic nanoplatforms as drug carriers. International Journal of Nanomedicine 7: 3445-3347.

Wang X, Podila R, Shannahan JH, Rao AM, Brown JM (2013) Intravenously delivered graphenenanosheets and multiwalled carbon nanotubes induce site-specific Th2 inflammatory responses via the IL33/ST2 axis. International Journal of Nanomedicine 8: 1733-1748.

Wani K, Tarawadi K, Kaul-Ghanekar R (2015) Nanocarriers for delivery of herbal based drugs in breast cancer-an overview. Journal of Nanoparticle Research 34: 29-40.

Want MY, Islamuddin M, Chouhan G, Ozbak HA, Hemeg HA, Dasgupta AK, Chattopadhyay AP, Afrin F (2015) Therapeutic efficacy of artemisinin-loaded nanoparticles in experimental visceral leishmaniasis.Colloids and Surfaces B: Biointerfaces 130: 215-221.

Watnasirichaikul S, Davies NM, Rades T, Tucker IG (2000) Preparation of biodegradable insulin nanocapsules from biocompatible microemulsions. Pharmaceutical Research 17: 684-689.

Wijagkanalan W, Kawakami S, Hashida M (2011) Designing dendrimers for drug delivery and imaging: Pharmacokinetic considerations. Pharmaceutical Research 28: 1500-1519.

Wu TH, Yen FL, Lin LT, Tsai TR, Lin CC, Cham TM (2008) Preparation, physicochemical characterization, and antioxidant effects of quercetin nanoparticles. International Journal of Pharmaceutics 346: 160-168.

Xiao X, Liu F, Shi C, Li L, Qin S, QiaoC, Su Z (1999) Rapd polymorphism and authentication of medicainal plants from turmeric (curcuma 1.) in china. Chinese Traditional and Herbal Drugs 31: 209-212.

XiaoYing L, Luo J, Yan Z, Rong H , Huang W (2006) Preparation and in vitro and in vivo evaluations of topically applied capsaicin transfersomes. Acta Pharmaceutica Sinica 41: 461-466.

Xu B, Chen X (2013) Electrical-driven transport of endohedral fullerene encapsulating a single water molecule. Physical Review Letters, 110: 156103.

Xu J, Fan QJ, Yin ZQ, Li XT, Du YH, Jia RY, Wang KY, Lv C, Ye G, Geng Y (2010) The preparation of neem oil microemulsion (azadirachtaindica) and the comparison of acaricidal time between neem oil microemulsion and other formulations in vitro. Veterinary Parasitology 169: 399-403.

Xue W, Zender L, Miething C, Dickins RA, Hernando E, Krizhanovsky V, Cordon-Cardo C, Lowe SW (2007) Senescence and tumour clearance is triggered by p53 restoration in murine liver carcinomas. Nature 445:65660 .

Yadav D, Suri S, Choudhary AA, Sikender M, Hemant Beg NM (2011) Novel approach: Herbal remedies and natural products in pharmaceutical science as nano drug delivery systems. International Journal of PharmTechResearch 3: 3092-3116.

Yadav M, Bhatia VJ, Doshi G, Shastri K (2014) Novel techniques in herbal drug delivery systems. International Journal of Pharmaceutical Sciences Review and Research 28:83-89.
Yan Y, JiHui Z, NianPing F, HaiTing W, YongTai Z(2010) Entrapment efficiency of podophyllotoxin-encapsulated ethosome by minicolumn centrifugation-hplc. Chinese Traditional and Herbal Drugs 41: 1634-1637.

Yao C, Yeh J, Chen Y, Li M, Huang C (2017) Wound-healing effect of electrospun gelatin nanofibres containing Centellaasiatica extract in a rat model. Journal of Tissue Engineering and Regenerative Medicine 11(3): 905-915.

Yen FL, Wu TH, Lin LT, Cham TM, Lin CC (2008) Concordance between antioxidant activities and flavonol contents in different extracts and fractions of cuscutachinensis. Food Chemistry 108: 455-462.

Yildirimer L, Thanh NTK, Loizidou M, Seifalian AM (2011) Toxicology and clinical potential of nanoparticles. Nanotoday 6: 585-607.

Yue PF, Yuan HL, Li XY, Yang M , Zhu WF (2010) Process optimization, characterization and evaluation in vivo of oxymatrine-phospholipid complex. International Journal of Pharmaceutics 387: 139-146.

Zabolotnyi MA, Momot AI, Dovbeshko GI, Gnatyuk EP, Solyanyk GI, Dmytrenko OP, Kulish NP, Fedina KV (2012) Modification of Alkaloid Structure in The Conium Drug With Fullerenes C60 M.A. Ukrainian Journal of Physics 57: 739-745.

Zhang C, Gu C, Peng F, Liu W, Wan J, Xu H, Lam CW, Yang X(2013) Preparation and Optimization of Triptolide-Loaded Solid Lipid Nanoparticles for Oral Delivery with Reduced Gastric Irritation. Molecules 18: $13340-13356$

Zhang H, Hou L, Jiao X, Ji Y, Zhu X, Zhang Z (2015a) Transferrinmediated fullerenes nanoparticles as fe2+-dependent drug vehicles for synergistic anti-tumor efficacy. Biomaterials 37: 353-366.

Zhang H, Ji Y, Chen Q, Jiao X, Hou L, Zhu X, Zhang Z (2015b) Enhancement of cytotoxicity of artemisinin toward cancer cells by transferrin-mediated carbon nanotubes nanoparticles.Journal of Drug Targeting 23: 552-567.

Zhang J, Jasti B, Li X (2007) Formulation and characterization of silibininloaded sterically stabilized solid lipid nanoparticles. Drug Delivery 15: 381-387.

Zhang L, Zhang 1, Zhang M, Pang Y, Li Z, Zhao A, Feng J (2015c) Selfemulsifying drug delivery system and the applications in herbal drugs. Drug Delivery 22: 475-486.

Zhao MX, Ji LN, Mao ZW (2014) Beta-Cyclodextrin / glycyrrhizic acid functionalized quantum dots selectively enter hepatic cells and induce apoptosis. Chemistry 18: 1650-1658.

Zhao Y, Wang C, Chow AH, Ren K, Gong T, Zhang Z, Zheng Y (2010) Self-nanoemulsifying drug delivery system (SNEDDS) for oral delivery of zedoary essential oil: Formulation and bioavailability studies International Journal of Pharmaceutics 383: 170-177.

Zhaowu Z, Xiaoli W, Yangde Z, Nianfeng L (2009) Preparation of matrineethosome, its percutaneous permeation in vitro and antiinflammatory activity in vivo in rats. Journal of Liposome Research 19:155-162.

Zhou Y, Wei Y, Liu H, Zhang G, Wu Xa (2010) Preparation and in vitro evaluation of ethosomal total alkaloids of sophoraalopecuroides loaded by a transmembrane pH-gradient method. AAPS PharmSci Tech 11: 13501358.

Zhu R, Qin L, Wang M, Wu S, Wang S, Zhang R, Liu Z, Sun X, Yao S (2009) Preparation, characterization, and anti-tumor property of podophyllotoxin-loaded solid lipid nanoparticles. Nanotechnology 20: 055702 .

Zolotarskaya OY, Xu L, Valerie K, Yang H (2015) Click synthesis of a polyamidoaminedendrimer-based camptothecin prodrug. RSC Advances 5: 58600-58608. 